\title{
Patrimonio rural y paleontológico en el noreste de Santa Cruz. Análisis de viabilidad para un circuito turístico sustentable
}

\author{
Rural and paleontological Heritage in northeast Santa Cruz province \\ Analyzing the viability for a sustainable tourist circuit \\ Mónica Patricia Menvielle, Patricia Sampaoli \\ mmenvielle@hotmail.com \\ Instituto de Cultura, Identidad y Comunicación (ICIC), UACO, UNPA \\ Caleta Olivia
}

Recibido: 18/03/2021. Aceptado: 25/06/2021

\begin{abstract}
RESUMEN
En este trabajo se analiza la viabilidad de un circuito turístico que incorpore las estancias del noreste de Santa Cruz, con su patrimonio histórico, arquitectónico y, en algunos casos arqueológico y paleontológico, y el Parque Nacional Bosque Petrificado de Jaramillo (PNBPJ), contribuyendo así a ampliar las posibilidades turísticas de esta región.

Luego de analizar la localización, contenido patrimonial y disponibilidad para la actividad turística, se consideran algunas estancias con aptitud para integrar el circuito propuesto. Una recorrida por este paisaje relata los cambios drásticos que sufrió el ambiente, a través de la historia de la Tierra y los cambios posteriores, introducidos por el hombre.

Se propone un circuito temático que abarque al menos una estancia y el PNBPJ: "Cambia, todo cambia: Santa Cruz, entre fósiles y ovejas". Sus atractivos principales están basados en el patrimonio histórico, arqueológico y paleontológico y, como atractivos complementarios, la gastronomía y actividades rurales, sin olvidar los de entorno, con puntos panorámicos.

Se considera factible desarrollar este circuito en un producto sustentable que beneficie a la comunidad local y aporte a la difusión de un yacimiento paleontológico de interés mundial.
\end{abstract}

Palabras clave: patrimonio cultural; turismo rural; turismo paleontológico; Santa Cruz.

\begin{abstract}
This work analyzes the viability of a tourist circuit that incorporates the "Estancias" (Rural Establishments) of the northeast of Santa Cruz, with its historical, architectural and, in some cases, archaeological and paleontological heritage, and Jaramillo Petrified Forest National Park (PNBPJ), thus contributing to expand the tourist possibilities of this region.

After analyzing the location, heritage content and availability for tourist activity, some Estancias with aptitude to integrate the proposed circuit are considered. A tour of this landscape recounts the drastic changes that the environment underwent throughout the history of the Earth and the subsequent changes, introduced by man.

A thematic circuit is proposed that covers at least one "Estancia" and PNBPJ: "Everything changes: Santa Cruz, among fossils and sheep". Its main attractions are based on the historical, archaeological and paleontological heritage and, as complementary attractions, the gastronomy and rural activities, without forgetting the surroundings, with panoramic points.
\end{abstract}


The feasible development of such a circuit is considered to become both, a sustainable product benefiting the local community and contributing to the diffusion of a paleontological site of world interest.

Keywords: Cultural Heritage; rural tourism; paleontological tourism; Santa Cruz.

\section{INTRODUCCIÓN}

La propuesta de relacionar turismo rural con turismo paleontológico surge a partir del trabajo como becaria en el marco del proyecto "Mundo rural en la primera mitad del siglo XX: Miradas interdisciplinarias para la recuperación y puesta en valor del patrimonio cultural del noreste de Santa Cruz", llevado adelante por un grupo consolidado de investigación del Instituto de Cultura, Identidad y Comunicación (ICIC), y teniendo en cuenta el propio proyecto de tesis que abarca un análisis comparativo de los Bosques Petrificados de Jaramillo (Santa Cruz) y Sarmiento (Chubut).

Este equipo interdisciplinario de investigación de la Unidad Académica Caleta Olivia de la Universidad Nacional de la Patagonia Austral, desde el año 2000, aporta conocimientos sobre la historia y el patrimonio cultural del noreste de la provincia de Santa Cruz, sobre todo en relación con el mundo rural. Esto permitió relevar un Patrimonio Rural importante que, no sólo enriquece la historia local y regional, sino que puede ser incorporado a desarrollos socioeconómicos sustentables. En trabajos anteriores, este equipo ha propuesto varios itinerarios culturales: "La Ruta de la Lana y su construcción signada por el trazado del Ferrocarril", "La Ruta de Las Huelgas de la década del 20" y "La Ruta del Petróleo".

Asimismo, en la misma zona, se encuentra el Parque Nacional Bosques Petrificados de Jaramillo (PNBPJ), que alberga y protege fragmentos de coníferas fosilizadas, algunas alcanzando los $35 \mathrm{~m}$ de largo y 3 de diámetro, que fueron sepultadas por las cenizas hace 150 millones de años. Esta área protegida permite observar un yacimiento paleontológico de importancia mundial y, a su vez, conserva una porción de la Estepa Patagónica con su flora, fauna y formas geológicas y también, sitios arqueológicos de los primeros cazadoresrecolectores de la zona.

El objetivo será analizar la viabilidad de un circuito turístico que incorpore las estancias del noreste de Santa Cruz y el PNBPJ, contribuyendo así a ampliar las posibilidades turísticas de esta región. Se debe pensar el aprovechamiento turístico de estos patrimonios: rural y paleontológico, de forma planificada, responsable y controlada, para no poner en peligro el futuro de los recursos disponibles. En definitiva, se analizará la viabilidad de una gestión sostenible y sustentable de un producto de turismo cultural en el noreste de Santa Cruz. El diseño de productos innovadores permitiría el desarrollo turístico en esta zona del amplio territorio provincial $\mathrm{y}$, además, podrían disfrutarse durante todo el año calendario, beneficiando a la comunidad local y aportando a la difusión de un yacimiento paleontológico de interés mundial.

Para lograrlo, se introduce en primer lugar, la historia del poblamiento del NE de Santa Cruz y el desarrollo del turismo rural, así como el origen y estado actual del PNBPJ. A continuación, el marco teórico-conceptual fundamenta la incorporación del patrimonio Paleontológico como patrimonio cultural y una mirada desde el Paisaje Cultural, sin dejar de lado el Turismo y la sustentabilidad.

Teniendo en cuenta las limitaciones que presenta la situación de Pandemia Covid-19, se utiliza una estrategia metodológica que combina procedimientos cuali-cuantitativos, analizando datos obtenidos por observación indirecta. Así, se estudia la localización, contenido patrimonial y disponibilidad para la actividad turística de las estancias recopiladas 
por el equipo anteriormente. Se revisa la información estadística oficial sobre actividad turística en la zona, incluyendo al PNBPJ.

Con estos datos se evalúan las posibilidades de aprovechamiento turístico y podrá confirmarse si es viable o no un circuito de este tipo.

\section{MARCO DE REFERENCIA}

\subsection{Marco Histórico}

\subsubsection{Poblamiento del NE de Santa Cruz: ganadería, ferrocarril}

Los primeros habitantes de la zona noreste de Santa Cruz fueron grupos de cazadoresrecolectores que ocuparon, hace aproximadamente 12.000 años, en principio la estepa y, con posterioridad, el bosque, los cordones montañosos y la costa (Borrero, 2009).

Hacia fines del siglo XIX la lana tenía gran demanda a nivel mundial y basándose en la labor desempeñada por los ganaderos de Malvinas, el Estado Nacional decidió favorecer la ocupación de estos territorios. El primer instrumento fue la ley de Inmigración y Colonización, del 14 de octubre de 1876 (ley N 817, llamada "Ley Avellaneda"), en la cual se sentaban las bases para la transferencia de tierras a particulares. La posesión y usufructo de la tierra podía ejercerse por: colonización directa del Estado, colonización de particulares, reducción de indígenas y por arrendamiento (Alonso, 1998).

Por colonización directa del Estado se crearon las colonias de Puerto Santa Cruz (1878) y de Puerto Deseado (1883). Esta propuesta no tuvo mucho éxito entre los habitantes del norte del país, pero sí se trasladaron de Islas Malvinas y del sur de Chile. Por este fracaso se decide disolver las Colonias de Puerto Deseado y Santa Cruz (1887) pero, a su vez, por medio de un decreto de 1885, se ofrecen tierras en Santa Cruz con un bajo costo y la posibilidad de elegir lugar. Así los pequeños propietarios de campos comienzan a transformarse en latifundistas, y da inicio a la explotación de la ganadería ovina (Alonso, 1998).

La ocupación de la zona sur de Santa Cruz, con mejores zonas de pastoreo, fue rápida. La zona norte fue considerada marginal, ya que la meseta era, y aún es, de baja receptividad ganadera (Ciselli, 2009).

Ya a principios de siglo XX los establecimientos asentados en el territorio obtenían excelentes resultados. Las estancias contaban con dos centros urbanos: Río Gallegos y Santa Cruz, donde se encontraban comercios importantes, como la Sociedad Anónima Importadora y Exportadora de la Patagonia, y bancos (filiales de Banco de Tarapacá y Londres).

El Estado Nacional intenta corregir el rumbo del reparto de tierras dictando la ley General de Tierras ( $\mathrm{N}^{\circ}$ 4167) en 1903. Se preveía así la exploración previa a la entrega, pero hizo poco por evitar los latifundios. A partir de 1904 el territorio se divide en zonas. La zona del río Deseado se encontraba prácticamente deshabitada. En 1908 se crearon en ella las Colonias de Las Heras, Presidente Manuel Quintana, Presidente Carlos Pellegrini, General Paz y Presidente Luis Sáenz Peña (Alonso, 1998).

El Decreto Reglamentario de la Ley General de Tierras exigía el poblamiento en forma personal, capital propio y la introducción durante los dos primeros años de al menos 500 ovejas u 80 vacas y plantar 100 árboles. Desde los inicios de la ocupación de la tierra, los trámites se realizaban en la Capital Federal. Esto provocó el surgimiento de gestores, intermediarios y "testaferros" (como el caso de la Estancia La Oriental) (Ciselli, 2009).

Hacia 1906, el Ministro de Agricultura, Dr. Ezequiel Ramos Mejía, expresaba su crítica por la forma de entrega de tierras. Por eso elaboró el proyecto de la ley de Fomento de Territorios Nacionales ( $\mathrm{N}^{\circ}$ 5559), que contemplaba, para la Patagonia: 
- Estudio, tendido y explotación de cuatro ferrocarriles que comunicarían los valles cordilleranos con los puertos y los valles entre sí.

- Construcción de muelles y depósitos para carga y descarga en los puertos.

- Limpieza y dragado del río Santa Cruz.

Se establecieron "zonas de influencia de los Ferrocarriles", con lotes para comercios y movimiento de ganado. El proyecto recién fue sancionado en 1908 (Alonso, 1998).

Estas dos últimas leyes fueron las que estaban vigentes al producirse la ocupación de la mayor parte del territorio noreste de Santa Cruz a fines del siglo XIX y comienzos del XX. Las mismas permitían la ocupación de hecho hasta concluir los trámites correspondientes; también permitían la obtención de un lote en propiedad de 2.500 hectáreas, en las Colonias Pastoriles o en las Zonas de Influencia del ferrocarril. Recién a partir de la década de 1920 comienzan a aparecer las mensuras, y en la década de 1950, los títulos de propiedad. A pesar de estas dificultades, para 1914 Santa Cruz se convirtió en el principal productor patagónico de lanas, con establecimientos de grandes superficies en el sur del territorio y considerablemente más pequeños en el norte del mismo. Posteriormente a Puerto Deseado, surgen algunos asentamientos urbanos, como Caleta Olivia, Mazarredo y Bahía Laura -estos dos últimos luego desaparecerían-, en los primeros años del siglo XX como consecuencia de la instalación del telégrafo entre Bahía Blanca y Cabo Vírgenes (1901) (Zubimendi y Sampaoli, 2020).

Otro impulso para crear asentamientos fue la construcción del Ferrocarril Patagónico. El 22 de julio de 1909 se colocó el primer riel y fue oficialmente puesto en funcionamiento el 31 de diciembre de 1913. Aunque el proyecto quedaba trunco a $283 \mathrm{~km}$ de haber nacido. La paralización de los trabajos en 1914 se fundamentó en la carencia de hierro que se volcó a fines bélicos debido a la guerra ítalo-turca, recientemente desatada. Se crean así las estaciones: Tellier, Pampa Alta, Antonio de Biedma, Cerro Blanco, Ramón Lista, Jaramillo, Fitz Roy, Tehuelches, Minerales, Pico Truncado Koluel Kaike, Piedra Clavada y Colonia Las Heras, que luego dan lugar a las poblaciones respectivas. Si bien el decreto nacional del 11 de julio de 1921 se toma como fecha fundacional de estas localidades, sólo se reconoce una situación de hecho anterior a la fecha del instrumento legal (Alonso, 1998).

Los poblados fundados por el ferrocarril tuvieron diversos destinos. Algunos han desaparecido, como Ramón Lista, Antonio de Biedma o Tehuelches; otros crecieron con la actividad lanera y, posteriormente, el petróleo y el gas, como Pico Truncado y Las Heras, o vinculadas al sector servicios, como Jaramillo, Fitz, Roy. Mientras que otros, como Koluel Kaike y Tellier, continúan en la actualidad como pequeñas poblaciones.

El sistema de pastoreo con campos abiertos se mantuvo durante la primera década del siglo $\mathrm{XX}$ hasta que estos fueron alambrados. El clima riguroso y la falta de agua hicieron que las casas de las estancias se ubicaran buscando la mayor protección natural posible. Por ello, la mayoría de los cascos y puestos se hallaban cerca de vertientes naturales, recostadas en las laderas de las mesetas o protegidas en los cañadones. Los establecimientos ganaderos del noreste de Santa Cruz eran, en términos generales, de pequeña extensión comparados con los otorgados en propiedad en la zona sur de la provincia y, sus primeros arrendatarios, de menor poder adquisitivo.

Desde la década de 1950 y, luego del descubrimiento del petróleo en la zona de Cañadón Seco, comienza su explotación generando una nueva estructura económica durante el período 1960-1980, que desplaza lentamente la actividad ganadera como actividad principal (Zubimendi y Sampaoli, 2020).

\subsubsection{Turismo Rural en Santa Cruz}

Desde finales del siglo XIX, la actividad productiva más extendida en la estepa patagónica ha sido la cría extensiva de ganado ovino. Pero, Caro, Zapata, Zanón, Rodríguez y Travaini 
(2017) indican que, en la provincia de Santa Cruz, esta actividad sólo fue rentable hasta mediados del siglo XX. A partir de entonces, la actividad ganadera ha disminuido de forma constante, afectada por factores climáticos como las sequías y heladas prolongadas, por la erupción del volcán Hudson en 1991, y por factores económicos, como la caída internacional en el precio de la lana y la inestabilidad de la economía argentina. Estos factores provocaron una profunda crisis en el sector ganadero y el cierre de cientos de establecimientos denominados localmente "campos" o "estancias".

Así, Pezzoni (2014) plantea que, en Argentina, el Turismo Rural comienza a desarrollarse en la Patagonia en la década de 1990. En la provincia de Santa Cruz el turismo rural, denominado localmente "turismo de estancias", tomó cierto impulso a partir del año 1992 (Scovenna, 2000), contando hacia el año 2000 con algo más de 30 establecimientos.

El INTA inició su apoyo al turismo rural, a mediados de la década de 1990, ante una suma de problemas que afectaba a los chacareros patagónicos. Con la erupción el volcán Hudson (Chile), cuyas cenizas afectaron una gran área, se vieron totalmente dañados cultivos y los rebaños ovinos quedaron virtualmente tapados, con lo cual la lana dejó de tener utilidad, sumado a otros factores económicos. Guastavino, Rozenblum y Trímboli (s/f) relatan que el INTA les propuso, a modo de prueba, a algunos de los afectados abrir sus tranqueras a la visita de turistas.

En 1996, a través de un proyecto elaborado en el Instituto de Economía y Sociología Rural del INTA, se crea la Red Argentina de Turismo Rural (RATUR), una organización cuyo funcionamiento llega a nuestros días, con una central de reservas de alojamientos rurales en el país. RATUR nuclea a más de 100 socios, establecimientos agroganaderos dedicados al turismo rural y brinda representatividad a sus integrantes, así como favorece que el establecimiento mantenga su actividad agropecuaria (Román y Ciccolella, 2009).

Después, el Programa Cambio Rural (de la Secretaría de Agricultura, Ganadería, Pesca y Alimentos), que había sido lanzado a principios de la década de 1990, resultó el instrumento para contener al primer grupo de productores agropecuarios que formalmente se organizó para prestar servicios de Turismo Rural en la Patagonia: fue el histórico Grupo Estancias de Santa Cruz, pionero en la actividad. En la actualidad es una entidad privada dedicada a difundir y promover el turismo de estancias y establecimientos alejados de centros urbanos en la Patagonia Austral. La organización, sin fines de lucro, agrupa establecimientos en las tres provincias australes patagónicas (Chubut, Santa Cruz y Tierra del Fuego). La entidad no recibe aportes externos, fue creada y se mantiene con el trabajo y el aporte de los más de 30 establecimientos que la integran (Román y Ciccolella, 2009).

Sin embargo, el gran impulso al turismo rural le fue dado por la firma del convenio entre la Secretaría de Turismo de la Nación (SECTUR) y la Secretaría de Agricultura, Ganadería, Pesca y Alimentación (SAGPyA) que tuvo lugar el 11 de mayo de 2000 y dio origen al Programa argentino de Turismo Rural "Raíces" (Schlüter, 2003). El mismo comprendía una serie de proyectos entre los que cabe mencionar al de las Rutas Alimentarias Argentinas y el Proyecto Municipio Rural Turístico. Este programa está destinado al sector rural, especialmente a los pequeños y medianos productores tradicionalmente generadores de materias primas, pero con posibilidades de realizar otras actividades para diversificar sus ingresos, entre ellas, el turismo rural (Román y Ciccolella, 2009).

Este programa se configura como el antecedente del Proyecto Nacional de Turismo Rural (PRONATUR), elaborado a fines de 2007 y coordinado por la SAGPyA, la SECTUR y el INTA. En este proyecto se prioriza la formación y capacitación de los distintos actores de la cadena de valor (productores, artesanos, organizaciones, comunidades locales, funcionarios de gobierno, etc.) y también se incorpora el uso de tecnologías de información (Román y Ciccolella, 2009). 
Jensen, Bouteiller y Zeinsteger (2001) entienden que la incorporación de la actividad turística al mundo rural significa la valorización de todo el potencial que tiene el campo y permite romper el actual esquema de monocultivo al diversificar sus productos/servicios, al mismo tiempo que se amplía la oferta de trabajo y posibilidades de desarrollo personal especialmente para los jóvenes y las mujeres, mejorando la calidad de vida. También es posible -a largo plazo- una mejora en la situación ambiental de los campos, ya que al diversificar las fuentes de ingresos se podría reducir la carga de ovinos por hectárea.

Entre 2005 y 2007, Caro et al. (2017) encuestaron mediante entrevistas a ganaderos y empleados de establecimientos ganaderos de la provincia de Santa Cruz, para explorar el conocimiento y las actitudes de los mismos hacia la incorporación de actividades económicas que podrían ser ambientalmente más sustentables que la ganadería ovina, como es el caso del Turismo.

Los resultados ponen de manifiesto cómo la actividad ganadera ovina en la provincia de Santa Cruz está en decadencia. La ganadería no representa una ocupación exclusiva y sólo constituye el único ingreso para una pequeña fracción de los encuestados. Por otro lado sólo el $13 \%$ de los establecimientos mantiene suficientes cabezas de ganado para considerar rentable su producción.

Aunque la mayoría de los encuestados muestran su disposición para realizar inversiones en sus establecimientos para desarrollar actividades alternativas a la ganadería ovina, también reconocen que estas serían demasiado costosas como para asumirlas sin ayuda. El 57\% de los ganaderos afirmó no poseer infraestructura para alojar y atender turistas y también reconocieron que carecían de conocimientos básicos para atención a los mismos. Por otro lado, una alta proporción de encuestados no renunciaría a mantener la carga ganadera, de manera que perciben los nuevos usos como complementarios más que como alternativos.

Dentro del Turismo rural, Ercolani y Seguí Llinás (2011) encuentran que la Patagonia presenta ventajas comparativas, que basadas en su patrimonio natural y cultural, unen el tardío poblamiento con un paisaje poco antropizado (en particular en algunas zonas) capaz de generar productos con alto valor agregado. Pero, tanto para el turismo internacional como para el doméstico, resaltan como problemática la falta de conectividad interna y externa, que se agrava, en particular, para acceder a los establecimientos que brindan prestaciones en el espacio rural, por el estado de las carreteras y la baja inversión en infraestructura e instalaciones.

En Patagonia se diferencian en principio dos niveles: nivel alto en el sentido económico, asociado al turismo de estancias, que además es el que recibe turismo receptivo internacional $\mathrm{y}$, minoritariamente, nacional; y las ofertas ligadas al agroturismo, con una demanda nacional, prioritariamente.

\subsubsection{Bosques Petrificados: formación y descubrimiento; de Monumento Natural a Parque Nacional}

En el período Jurásico (205 a 145 millones de años), la cordillera de los Andes no existía. Una entrada del océano Pacífico, formaba un mar epicontinental, que cubría gran parte de las provincias de Neuquén, Mendoza, Río Negro y La Pampa. La Patagonia gozaba de un clima cálido y uniforme. Sin barreras orográficas, los vientos húmedos del Pacífico llegaban a lo que es ahora una árida meseta. En el este, a su vez, no se había formado aún el Océano Atlántico que separaría nuestro continente de África (Pisano y Halpern, 2009).

En la región nororiental de Santa Cruz, en el llamado Macizo de Deseado, crecían frondosos bosques de Coníferas. Pisano y Halpern (2009) comentan que, habitualmente se dice que los dinosaurios dominaron la tierra, pero, entre las plantas también había un predominio, y este fue el caso de las coníferas. 
En el Jurásico medio a superior (165 a 155 MA), ocurre un importante evento volcánico y sedimentario relacionado con la ruptura de la corteza continental y la formación del Océano Atlántico Sur. Estuvo caracterizado por potentes erupciones de tipo explosivo y el territorio fue azotado por vientos huracanados, que derribaron muchos árboles y produjeron la extinción de los bosques. Las nubes de ceniza sepultaron los árboles caídos, que estaban cargados de estróbilos (piñas) maduros o próximos a la madurez (Cúneo y Panza, 2008).

Spegazzini (1924) consideró que esos estróbilos estudiados eran jóvenes (no mayor a seis meses después de la fecundación) y arrancados del árbol por algún violento esfuerzo mecánico (como un huracán) y caído de inmediato en el líquido silicificante y sufrido en seguida su acción.

Por el proceso de permineralización, las sales de silicio - disueltas por el paso del agua de lluvia a través de las capas de ceniza- reemplazaron los componentes orgánicos de la madera, copiando con extrema fidelidad su estructura.

Después de millones de años, el viento y la lluvia descubrieron nuevamente el bosque, ahora fosilizado.

Suero (1959) explica que la denominación "bosques petrificados", debería restringirse a aquellos conjuntos de restos, improntas o vestigios de árboles, que revelen con claridad hallarse emplazados hoy día en los mismos lugares donde nacieron y crecieron las plantas y árboles correspondientes a tales restos fosilizados. Este es el caso que se analiza.

También salieron a la luz talleres líticos, enterratorios y otros indicios de la presencia de primitivos cazadores-recolectores, protagonistas de la ocupación más antigua de este territorio (12.000 años), y que han dado lugar a investigaciones arqueológicas (Miotti y Salemme 2004; Miotti et al., 2009; Magnin y Blanco, 2018).

Suero (1959) atribuye a Anselmo Windhausen, a quien la Dirección General de los Yacimientos Petrolíferos Fiscales le había encargado la exploración y el relevamiento geológico de la zona petrolera de Chubut y Santa Cruz (ANC, 2019), el hecho de encontrar "in situ", a principios de 1922, los primeros estróbilos de araucarias en las inmediaciones del Cerro Alto. Envió muestras de fósiles ("Araucaria mirabilis") a su colega alemán Walter Gothan, célebre paleontólogo, para su estudio en Alemania.

Gothan las describió como Araucaria Windhauseni pero, antes de aparecer la contribución conjunta de ambos hombres de ciencia, en 1924, Carlos Spegazzini, el gran botánico, describió tres estróbilos similares a los que estudiara Gothan, a los que describió como Araucarites mirabilis, provenientes de las inmediaciones del Cerro Madre e Hija y que le llegaron por otros medios (Suero, 1959).

Antes de que gozara de protección, el bosque fue despojado de piñas, ramas e incluso enormes troncos. Vizcaíno, Bargo y Fernicola (2012) entienden que los fósiles santacruceños han sido utilizados como valores de cambio entre científicos e instituciones, de acuerdo con prácticas comunes y regulaciones que las permitían (en la mayoría de los casos).

Aún entre sus visitantes actuales resulta costumbre el intento de "robo hormiga". En un solo año, los guardaparques secuestraron nada menos que sesenta kilos de fragmentos petrificados (MMA, 2005).

Su protección llegó con el Decreto Nacional N7.252/54. Así, en 1954, se reserva para la Administración de Parques Nacionales (APN), una sección del Territorio de Santa Cruz, con una extensión de 10.000 ha, sobre la propiedad de El Bajo, con fines de utilidad pública, declarándola Monumento Natural.

Carreras Doallo (2012) plantea que, durante el peronismo histórico (1946-1955), las áreas correspondientes a Parques Nacionales se incrementan notablemente y se imponía la frase "conocer la Patria es un deber".

En 1984, el Consejo Agrario de Santa Cruz resuelve incorporar 5000 ha, ya que en realidad, el bosque petrificado había quedado fuera del la demarcación del Monumento Natural. Hacia 
fines de 1990, la APN adquiere las estancias vecinas Cerro Horqueta y El Cuadro. Así se crea el Parque Nacional el 27 de diciembre de 2012, mediante Ley $\mathrm{N}^{\circ} 26.825$, agregando al importante yacimiento paleontológico, la protección de una muestra representativa de la Estepa patagónica central, los humedales, las formaciones geológicas y, también, los sitios arqueológicos e históricos (APN, 2018).

\subsection{Marco teórico-conceptual}

\subsubsection{Patrimonio cultural, patrimonio rural y paleontológico}

Etimológicamente el Patrimonio nos refiere a aquello que proviene de los padres. Ampliando ese concepto, se podría definir el patrimonio como el conjunto de elementos o manifestaciones materiales o inmateriales que constituyen el acervo de las sociedades. Pero este concepto se ha ido modificando con el tiempo, se ha ido construyendo. Se puede vincular el patrimonio con la identidad y la herencia diciendo que es la síntesis de los valores que dan identidad a una sociedad que los reconoce como propios. Ballart Hernández y Treserras (2008) sostienen que el patrimonio histórico está constituido por objetos que permanecen a pesar del paso del tiempo (en uso, en un museo, etc). Ese paso del tiempo es la esencia de la historia. Por lo tanto, esos objetos son la materialización de la historia y relacionan el pasado con el presente. Así, el patrimonio, como herencia cultural, conecta a los seres humanos del ayer con los del presente, beneficiando su riqueza cultural y su identidad. Los recursos patrimoniales son escasos y no renovables. Se deben establecer prioridades para conservar los elementos más importantes y representativos. Para ello Ballart (1997) indica que el proceso de selección y puesta en valor se hace a partir de los valores de referencia que incluyen: el valor de uso tangible e intangible, el valor formal o estético y el valor simbólico o asociativo.

Para Troncoso y Almirón (2005), esta es una concepción estática en la cual la sociedad es sólo receptora y transmisora del patrimonio, y debería verse como un legado en constante transformación. La cultura y, por tanto, sus manifestaciones son cambiantes. Refieren así el concepto introducido por Prats (1997) indicando que, el criterio fundamental para considerar el Patrimonio no será ni la antigüedad, ni la originalidad, sino la eficacia simbólica.

Luego Prats (2000) complejiza más la idea y establece un triángulo formado por la naturaleza, la historia y la genialidad, que contiene los elementos (materiales e inmateriales) potencialmente patrimonializables. Esos elementos son activados por versiones ideológicas de la identidad (entendida como una construcción social y, por lo tanto, dinámica). Aunque la sociedad civil puede activar repertorios patrimoniales, es el poder formal (gobierno) e informal, quien principalmente lo hace. Este patrimonio activado, es decir, seleccionado para ser expuesto, forma parte de una versión hegemónica de la identidad y puede no ser compartido por algunos sectores.

Hablando específicamente de Patrimonio Cultural, García López (2008) lo reconoce como

“...parte y resultado de la interacción del ser humano con sus semejantes y con su entorno, un artificio de su creación y, por tanto, reversible y dinámico. Además, lo que es susceptible de ser considerado Patrimonio Cultural va más allá de lo fabricado manualmente por el hombre incluyendo todo lo manipulado inteligentemente por este" (p. 2).

Cortijo Gil (2013) propone un concepto de Patrimonio Rural como el conjunto de elementos materiales e inmateriales que testimonian las relaciones particulares que una comunidad humana ha establecido en el curso de la historia con un territorio.

El concepto de patrimonio Rural, como parte del Patrimonio Cultural, no es homogéneo, incluye: los edificios, lo que se conoce como arquitectura rural, los productos de la tierra, las técnicas, herramientas y conocimientos que han posibilitado su creación y también los 
símbolos y los significados culturales, y, por supuesto, el paisaje modelado en el transcurso del tiempo.

Incluir al Patrimonio Paleontológico ${ }^{1}$ dentro del Patrimonio Cultural, no es tan sencillo. Algunos autores, como Díaz Martínez, Carcavilla y García Cortez (2013), consideran que los fósiles son elementos naturales de tipo geológico y, por lo tanto, como los fósiles no son resultado de la actividad antrópica, consideran que no tiene ningún sentido tratarlos como elementos culturales, ni considerar el patrimonio paleontológico como patrimonio cultural.

Sin embargo, en la Mesa Redonda de Patrimonio en las XXV Jornadas Argentinas de Paleontología de Vertebrados, realizada en mayo de 2010 en San Luis (Arcucci y Prado, 2010), se planteó que la Paleontología es inseparable de la Geología y por consiguiente los yacimientos paleontológicos son indisociables de los cuerpos geológicos y del entorno geológico-paisajístico en los que se encuentran. Pero, para considerar la pertenencia de los bienes paleontológicos a una u otra categoría se debe tener en cuenta que, si se atiende al origen y naturaleza de los objetos paleontológicos -fósiles y yacimientos- su protección debería enmarcarse dentro del patrimonio natural, ya que se trata de objetos naturales no creados por la actividad del hombre. Pero además se debe considerar que es constitutivo de estos objetos, y de la propia ciencia que los estudia, su dimensión histórica y su pertenencia a un período determinado de la historia de la Tierra. Por esta razón, resulta justificado que los bienes paleontológicos se integren dentro del Patrimonio Histórico, y por lo tanto, Cultural.

A pesar de la ambigüedad que presenta la inclusión de este Patrimonio dentro del Patrimonio Histórico, Castillo et al. (1999) la defienden, siempre que se produzca la ampliación del valor cultural que fundamenta este concepto, lo que supondría considerar la historia de la vida, la propia evolución, como valor a proteger. Entre los que incluyen el tratamiento de los objetos paleontológicos dentro del Patrimonio Histórico, pueden destacarse la mayoría de las leyes sobre el tema aprobadas en el ámbito europeo (por ej. la ley 16/1985 de Patrimonio Histórico Español).

Tomando como referencia la legislación argentina vigente, la ley nacional 25.197 de Régimen del registro del Patrimonio cultural establece que "el producto de las exploraciones y excavaciones arqueológicas y paleontológicas, terrestres y subacuáticas" son considerados bienes culturales históricos. La propia ley 25.743, de Protección del Patrimonio Arqueológico y Paleontológico, lo refleja claramente en su art. $1^{\circ}$ : "es objeto de la presente ley la preservación, protección y tutela del Patrimonio Arqueológico y Paleontológico como parte integrante del Patrimonio Cultural de la Nación y el aprovechamiento científico y cultural del mismo".

Considerando la legislación de la provincia de Santa Cruz, la ley $\mathrm{N}^{\circ} 3137$ del Patrimonio Arqueológico y Paleontológico, adhiere a la ley nacional y crea un registro del mismo, a cargo de la Dirección de Patrimonio Cultural. Siguiendo esta línea la Subsecretaría de Cultura publica el "Estado actual de las investigaciones realizadas sobre patrimonio cultural en Santa Cruz", donde incluye las investigaciones Paleontológicas.

Siguiendo el concepto de Castillo et al. (1999) y la legislación actual, se considera en este trabajo, el Patrimonio Paleontológico dentro del Cultural.

\subsubsection{Paisaje Cultural, paisaje arqueológico y paleontológico}

En 1972 la UNESCO incorpora la categoría de Paisaje Cultural, concepto que incluye una diversidad de manifestaciones producto de la interacción entre el hombre y su ambiente

\footnotetext{
${ }^{1}$ Art. $2^{\circ}$ : ... Forman parte del Patrimonio Paleontológico los organismos o parte de organismos o indicios de la actividad vital de organismos que vivieron en el pasado geológico y toda concentración natural de fósiles en un cuerpo de roca o sedimentos expuestos en la superficie o situados en el subsuelo o bajo las aguas jurisdiccionales. (Ley 25.743 de Protección del Patrimonio Arqueológico y Paleontológico)
} 
natural. En 1992 se adoptan tres categorías para el Paisaje Cultural: los paisajes "diseñados", concebidos y creados por el hombre, los paisajes esencialmente cambiantes "evolutivos" y los "asociativos" de aspecto religioso, artístico o cultural (Arias Incollá, 1999).

Sampaoli et al (2018) describen, los cuatro tipos de paisajes culturales que el National Park Service de Estados Unidos ha determinado para su gestión: Sitio Histórico, Paisaje Histórico Diseñado, Paisaje Histórico Vernáculo y Paisaje Etnográfico. El Paisaje será Histórico por su relación con un acontecimiento histórico, una actividad o un personaje; Histórico Diseñado, el proyectado por un paisajista, un maestro jardinero, un arquitecto, etc.; Histórico Vernáculo, el que ha evolucionado con el uso de la gente y Etnográfico, con diversos elementos naturales y culturales que sus habitantes reconocen como recursos patrimoniales.

En Santa Cruz, desde el auge de la lana a la explotación petrolera, el paisaje ha ido cambiando junto con las actividades y los actores sociales.

Por su lado, Magnin, Miotti y Hermo (2018) analizan la relación que grupos de cazadores recolectores tuvieron con el ambiente en lo que es hoy el PNBPJ. El entorno geográfico fue habitado por individuos y comunidades durante extensos periodos de tiempo, por lo que se establecen lazos con distintos aspectos de la vida humana. Así, el paisaje se fue estructurando y "enculturando" a través de las prácticas sociales, simbólicas y rituales. Por ello, los rasgos naturales del paisaje pueden apropiarse simbólicamente, formando parte del mundo cultural sin que haya intervenciones materiales sobre los mismos.

Durante milenios se sucedieron las ocupaciones humanas y el paisaje se transformó en humanizado y con historia. A través del tiempo se produjeron distintas formas de interacción con el entorno, desde los cazadores recolectores hasta la instalación de los establecimientos ganaderos a comienzos del XX.

Siguiendo a Endere y Prado (2009), se puede decir que los yacimientos paleontológicos son indisociables del entorno geológico-paisajístico en los que se encuentran. A nivel internacional es cada vez más generalizada la tendencia a usar la categoría de paisaje en vez de la de yacimiento. Así por ejemplo, el Convenio Europeo del Paisaje (Consejo de Europa, 2000, en Endere y Prado, 2009) propone al paisaje como la unidad primaria de análisis del patrimonio común europeo, "el cual requiere de un abordaje amplio y comprensivo de todos sus aspectos, de la participación democrática y de un manejo sustentable" (p. 53).

Endere y Prado (2009) explican que

"esta perspectiva de caracterización de los paisajes culturales o históricos considera todos los aspectos naturales y culturales, antiguos y modernos. Tiene en cuenta las percepciones de las comunidades locales y no sólo la opinión experta, ya que considera a los paisajes como una cuestión de interpretación más que de registro de elementos objetivos" (p. 53).

\subsubsection{Patrimonio, turismo y sustentabilidad}

El turismo cultural constituye, hoy en día, un segmento turístico en expansión, convirtiéndose en un importante protagonista de la recuperación urbanística, arquitectónica y funcional de muchos lugares. El crecimiento de este turismo está relacionado con la aparición de un nuevo turista, preocupado por acercarse y conocer la naturaleza y las culturas, que busca consumir nuevos productos (Troncoso y Almirón, 2005).

Considerando del patrimonio cultural desde una perspectiva turística, está integrado por todos aquellos atractivos capaces de motivar el viaje. Dentro de las relaciones que se establecen entre anfitriones y turistas, se debe tener en cuenta la atracción que pueden provocar determinados aspectos de la cultura de los primeros; fundamentalmente ciertos elementos tangibles, como pueden ser la arquitectura tradicional, la producción artesanal o la gastronomía (Pastor Alfonso, 2003). 
Un lugar puede darse a conocer a través de sus elementos patrimoniales; así, el turista se llevará la imagen que sus anfitriones le ofrezcan y esto, además de proporcionar un beneficio económico, servirá para reforzar la estima que, sobre sus factores identitarios, tienen los pobladores. Al ser el patrimonio cultural algo dinámico, hay muchos factores que lo afectan, por ejemplo, el turismo.

Algunas veces el Patrimonio es considerado como un atractivo turístico por sí mismo, pero se debe investigar su aptitud o vocación turística y las reales posibilidades de aprovechamiento.

Prats (1997) recuerda que la relación entre patrimonio y turismo no es un hecho reciente. El patrimonio ha sido uno de los primeros motivos de viaje antes de hablar de turismo como se lo entiende ahora. Pero la masificación de la actividad produce un cambio en la relación entre patrimonio y turismo. Se dan activaciones patrimoniales promovidas por el turismo, donde se reflejan confrontaciones entre la lógica turístico-comercial y la lógica identitaria. También advierte sobre las políticas de espectacularización y comercialización del patrimonio. Por eso, sentencia: "el turismo puede representar para el patrimonio ingresos, vitalidad y relevancia política, pero no a costa de un mercantilismo abusivo..." (Prats, 2003, p. 135)

Fernández y Guzmán Ramos (2002) señalan los efectos del turismo sobre el patrimonio en sentido amplio: contaminación arquitectónica, sobrecarga en la infraestructura y pérdida de calidad del destino. También los residuos pueden afectar el patrimonio histórico cultural en forma indirecta (por ejemplo: contaminación visual, olores, etc.). A esto se agrega la congestión del tránsito, el depósito de residuos en la vía pública, etc. Por otro lado, así como el turismo puede ayudar a preservar las culturas, también alienta formas culturales "pseudo tradicionales".

Troncoso y Alirón (2005) indican que hay un acuerdo general que sostiene que, dentro de un desarrollo sustentable, que evite repetir los efectos del turismo masivo, esta actividad puede ser una fuente de recursos económicos para la gestión, protección y conservación de este patrimonio y para el desarrollo en general, pero no debe naturalizarse la relación positiva entre turismo y patrimonio.

En términos generales se entiende por desarrollo sustentable aquel que satisface las necesidades de las generaciones presentes sin comprometer el derecho de las generaciones futuras de satisfacer sus propias necesidades. Los términos "sustentabilidad" y "sostenibilidad" se usan muchas veces de manera indistinta. Sin embargo, Rivera Hernández, Blanco Orozco, Alcántara Salinas, Houbron y Pérez Sato (2017) recuerdan que, por un lado el vocablo "sostenible" tiene su origen en la palabra "sostenido", cuyo significado es que algo puede mantenerse por un tiempo determinado; por eso, "sostenible" significa que algo se puede mantener por tiempo indefinido, sin que colapse o se deteriore. Por su parte, "sustentable" se origina del verbo "sustentar', cuyo significado se enfoca hacia un proceso independiente, que no necesita de recursos externos para mantenerse. Así, “... al referirse al desarrollo y asociarle el término "sustentable" debe entenderse que se está expresando un proceso de desarrollo equilibrado desde los puntos de vista social y económico y su interacción con el ambiente. Por su parte, el 'desarrollo sostenible' se refiere a un proceso con características económicas que le permite al sistema perdurar en el tiempo" (Rivera Hernández et al, 2017, p. 64).

En el desarrollo turístico, para Monfort Mir (2010), la sostenibilidad se basa en el óptimo uso de los recursos ambientales, respetando los procesos ecológicos, la conservación de los recursos naturales y la diversidad biológica. De igual forma, hace hincapié en el respeto por la autenticidad sociocultural de las comunidades anfitrionas, conservando sus recursos patrimoniales y sus valores tradicionales. Así, el patrimonio cultural, convertido en objeto de consumo, puede ser una fuente de ingresos para una comunidad, pero también puede permitir un desarrollo integral, siempre que sea definido, construido y reconocido por la sociedad misma. En ese caso, tendrá el valor de autorreconocimiento de los individuos y grupos en su 
pasado y su presente, recuperando su autoestima y, además, transformarse en una "memoria colectiva" que ayude a enfrentar dificultades (Zamora Acosta, 2011).

\subsection{Marco Legal}

En Argentina la preservación y protección del patrimonio cultural es un derecho de la comunidad y, por lo tanto, las autoridades están obligadas a proveer lo necesario a los fines de la preservación, y se ve reflejado como un derecho colectivo de la máxima jerarquía en la Constitución Nacional (arts. 41 y 43).

Diversos documentos internacionales fundamentan este concepto, entre ellas: la Carta de Atenas (1931), que propuso criterios destinados a propiciar la "continuidad vital" del patrimonio; la Carta de Venecia (1964), enfocada a la protección de los vestigios materiales del patrimonio cultural; el Documento de Nara sobre Autenticidad (1994), resaltando la importancia del contexto cultural, la Carta Internacional de Arquitectura Vernácula (1996), que detalla el modo de actuar ante este patrimonio; la Carta Internacional sobre el Turismo Cultural (1999), cuyo objetivo principal fue brindar criterios para favorecer la compatibilización entre turismo, intercambio cultural y preservación patrimonial, entre otras.

Para lograrlo se han dictado varias leyes. La ley Nacional 12.665/40 crea la Comisión Nacional de Museos, Monumentos y Lugares Históricos (Boletín Oficial del 15 de octubre de 1940), modificada en el año 2015 por la ley 27.103, pasando a llamarse Comisión Nacional de Monumentos, de Lugares y de Bienes Históricos. La ley nacional 25.197/99 establece el Régimen del registro del Patrimonio Cultural.

Por otro lado, la ley nacional de Áreas Protegidas es la Ley $\mathrm{N}^{\circ} 22.351$, sancionada en 1980, y la Administración de Parques Nacionales es la autoridad responsable del manejo de los recursos culturales en los parques y reservas nacionales.

La ley Nacional 25.743, de Protección del Patrimonio Arqueológico y Paleontológico, es de relativamente reciente sanción (2003), así como la ley de creación del Parque Nacional Bosques Petrificados de Jaramillo, Ley N 26.825 del año 2012.

En la provincia de Santa Cruz, dos leyes recientes (2010) se ocupan del Patrimonio Cultural. La ley provincial 3137 adhiere a la ley Nacional 25743 de Protección del Patrimonio Arqueológico y Paleontológico e incluye también los Paisajes Culturales; mientras que la ley provincial 3138 se refiere a la protección del Patrimonio Cultural y Natural, Arquitectónico, Urbano y rural.

En lo referido al Turismo rige la ley Nacional 25.997/05 y el Plan Federal Estratégico de Turismo sustentable que se actualizó en 2015. En la provincia de Santa Cruz está vigente una ley de 1976 que rige la actividad turística, la ley provincial 1045, a la cual se agrega en 2010 la ley provincial 3134, la cual aporta el capítulo V sobre Turismo Rural. También en 2010 se dicta la ley provincial 3187, de Deporte, Recreación y Turismo social.

\section{RESULTADOS, ANÁLISIS Y DISCUSIÓN}

\subsection{Metodología}

El diseño de la investigación es de tipo descriptivo con una estrategia metodológica que combina procedimientos cuali-cuantitativos. Esto permite describir e interpretar los datos existentes, construidos como resultado de la observación indirecta (recursos cartográficos, imágenes satelitales, fotografías, gráficos, estadísticas, etc.), así como los aportes de investigaciones anteriores. 


\subsection{Resultados}

\subsubsection{Información sobre la actividad turística en Santa Cruz}

El Ministerio de Turismo y Deportes de la Nación, a través de la Dirección Nacional de Mercados y Estadísticas, brinda importante información sobre el desarrollo turístico en Santa Cruz. Tomando un promedio desde 2012 a 2019, Santa Cruz recibe igual proporción de turistas extranjeros y residentes y representan el $1 \%$ del total de turistas que recorren el país. La actividad presenta una marcada estacionalidad en el $1^{\circ}$ trimestre del año. Con respecto al alojamiento, muestra que el $72 \%$ de las plazas se ubican en El Calafate, El Chaltén y Río Gallegos (anexos 1, 2 y 3 ).

El órgano oficial de Turismo en la provincia de Santa Cruz es la Secretaría de Estado de Turismo dependiente del Ministerio de la Producción, Comercio e Industria. Este organismo ha presentado el Observatorio Económico del Turismo provincial (OETuSC) que

\begin{tabular}{|c|c|}
\hline \multicolumn{2}{|c|}{ Listado de Estancias turísticas en Santa Cruz } \\
\hline Localidad cercana & Cantidad de estancias \\
\hline Río Gallegos & 6 \\
\hline El Calafate & 9 \\
\hline El Chaltén & 6 \\
\hline Gobernador Gregores & 6 \\
\hline Perito Moreno & 1 \\
\hline Río Turbio & 3 \\
\hline Puerto San Julián & 1 \\
\hline Piedrabuena & 1 \\
\hline Puerto Deseado & 2 \\
\hline Tres Lagos & 1 \\
\hline Lago Posadas & 1 \\
\hline
\end{tabular}

Tabla 1- Estancias turísticas en Santa Cruz. (Elaboración propia con base en datos del Manual turístico 2018- Sec. de Estado de Turismo Santa Cruz) pretende generar un sistema de estadísticas turísticas integrado, para favorecer la toma de decisiones. Esta Secretaría agrega información sobre el turismo rural en la provincia (Tabla 1).

El observatorio, en agosto 2020, realizó una encuesta de expectativas de viaje pos aislamiento, relevando la información de potenciales turistas interesados en viajar por la provincia. En los resultados se observa que el $50 \%$ de los encuestados residen en Santa Cruz. Al preguntarles: "Si la cuarentena terminara la próxima semana, ¿qué destinos tiene en mente para su primer viaje?", el 97,1 $\%$ prefirió destinos dentro del país y, dentro de ellos, el 52,1\%, en Santa Cruz. (Anexo 4).

Con la visión de consolidar a Santa Cruz como un destino turístico de preferencia en el Turismo interno y en la región Patagonia para el Turismo receptivo, la Secretaría elaboró un plan de promoción turística 2018-2019. Analizando las fortalezas, señala el hecho de que es la provincia con mayor cantidad de Parques Nacionales y áreas protegidas. Por ello es importante considerar el uso turístico de estas áreas.

El Ministerio de Turismo y deporte informa la cantidad de visitas a los Parques Nacionales, durante el año 2019, discriminado por condición de residencia. Se elabora, por lo tanto, un extracto con los que corresponden a Santa Cruz. (Tabla 2)

\begin{tabular}{l|rr} 
Parque Nacional & Residentes & No residentes \\
\hline Los Glaciares & 307.407 & 464.114 \\
Monte León & 2.778 & 837 \\
Bosques Petrificados & 2.770 & 866 \\
Perito Moreno & 606 & 423 \\
\hline
\end{tabular}

Tabla 2- Visitas a los Parques Nacionales en Santa Cruz. Año 2019. (Fuente Min. de Turismo y Deporte) 


\subsubsection{Uso público del Parque Nacional Bosques Petrificados de Jaramillo}

El plan de gestión del Parque Nacional Bosques Petrificados de Jaramillo (PNBPJ) y Monumento Natural Bosques Petrificados fue elaborado y presentado recientemente, en 2018. Los objetivos de conservación del PNBPJ son:

- Preservar la integridad y permanencia de los yacimientos fosilíferos, especialmente los de coníferas del Jurásico.

- Conservar una muestra representativa del ecosistema de la estepa patagónica central.

- Conservar los humedales y las especies asociadas a estos ambientes.

- Preservar los sitios arqueológicos e históricos que evidencian las ocupaciones humanas del sector durante el Holoceno.

- Valorizar las formaciones geológicas y los procesos geomorfológicos del área.

Dentro de los recursos culturales se incluyen sitios arqueológicos de ocupaciones que se remontan a 12.000 años aP, sitios históricos que forman parte de las tres estancias donde se estableció el área protegida, y el patrimonio cultural inmaterial, relato de los trágicos sucesos ocurridos entre 1919 y 1922, asociado a las huelgas de peones rurales. (APN, 2108)

Todo esto lo convierte en un importante atractivo turístico. Pero, al ser un área protegida (AP), debe considerarse con atención el uso público.

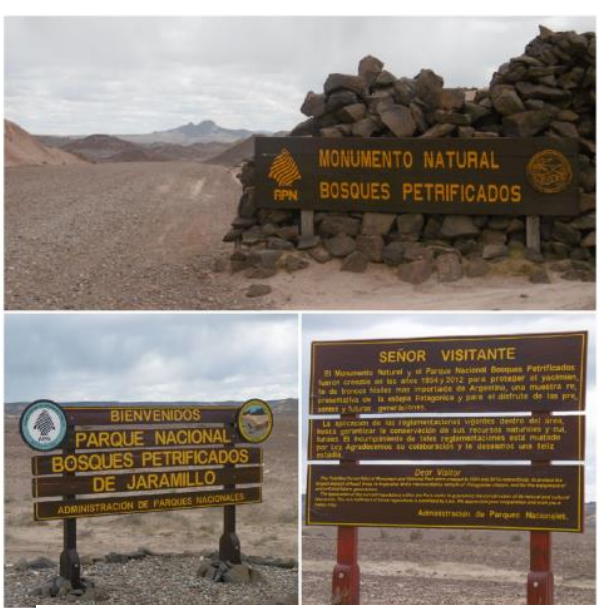

Ilustración 1- Cartelería Acceso a PNBPJ

(Fuente M. Menvielle- 2020)

Accesos: La vía de acceso al AP para el público visitante es

la $\mathrm{RP} \mathrm{N}^{\circ}$ 49. Esta ruta provincial de ripio une la $\mathrm{RN} \mathrm{N}^{\circ} 3$ con la $\mathrm{RP} \mathrm{N}^{\circ} 12$, atravesando el PNBPJ de este a oeste. Se encuentra en buen estado de mantenimiento y posee cartelería institucional en su acceso por RN 3.

Horarios de visita: El AP se encuentra abierta al público todo el año, con un horario de visita de 10 a 17 horas entre el $1^{\circ}$ de abril y el 30 de septiembre, y de 9 a 19 hs desde el $1^{\circ}$ de octubre hasta el 31 de marzo.

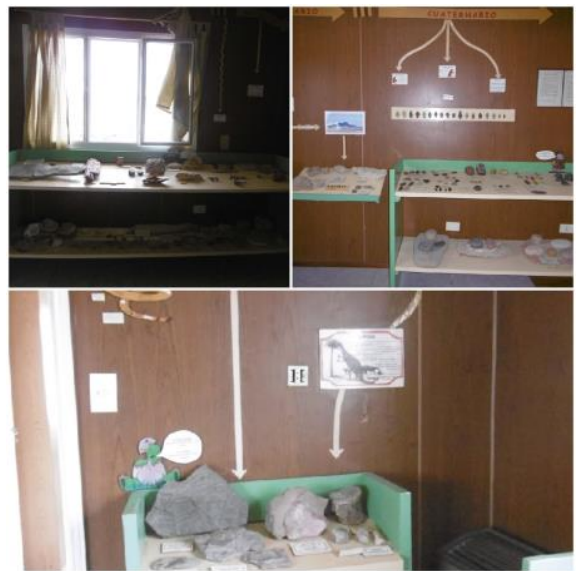

Ilustración 2- Muestra interpretativa en el Centro para visitantes (Fuente M. Menvielle 2020)
Cobro de derechos de acceso: El ingreso es libre y gratuito. No se prevé el cobro de derechos de acceso a mediano plazo.

Infraestructura para atención de los visitantes: El sector destinado a visitantes, ubicado a $12 \mathrm{~km}$ del Portal, consta de una oficina de reducidas dimensiones y otro sector que alberga una muestra interpretativa. Aledaño a la vivienda del personal se encuentra un único sanitario público. El Plan de Manejo informa que, en la actualidad, considera las instalaciones inadecuadas para la correcta atención del público.

Sectores habilitados a la visita:

- Recorrido vehicular: El único circuito habilitado para los visitantes -hasta el presente- es la RP $\mathrm{N}^{\circ} 49$, que permite recorrer $36,5 \mathrm{~km}$, atravesando el AP en sentido este - oeste. Se prevé la ampliación mediante la habilitación al uso público de dos caminos internos, que permitirán el acceso a los ex cascos de las estancias El Cuadro y Cerro Horqueta. 
- Sendero paleontológico "Las Huellas de Pasado": Es el único circuito peatonal habilitado hasta el presente. Posee una extensión total de $2.000 \mathrm{~m}$ y su traza, en forma de "ocho", tiene un solo sentido de circulación. La duración aproximada del recorrido es de 1 hora. Como alternativa se puede recorrer la parte más corta, de solo $620 \mathrm{~m}$.

El sendero es de dificultad media, con relieve ondulado. Toda la traza presenta material paleontológico en superficie. Tiene solamente cartelería indicativa de sentido de circulación y algunos nombres de plantas.

Visitación: puede clasificarse como "de paso", principalmente condicionada por la falta de sitios para pernoctar en el interior de la misma. Existen datos de números de visitantes desde el año 1989 a la fecha. Se observa una tendencia en aumento hasta el año 2004, a partir de esa fecha el número de visitas empezó a disminuir.

Información y atención al visitante: La cartelería informativa es escasa y no del todo apropiada, por ejemplo la ubicada sobre la $\mathrm{RN} \mathrm{N}{ }^{\circ} 3$ no tiene el tamaño de letra adecuado. La oficina de informes cuenta con personal permanente dentro de los horarios de visita.

Áreas de acampe: En la actualidad el AP no cuenta con áreas de acampe habilitadas. La opción más cercana es el Camping La Paloma, ubicado sobre la RP $\mathrm{N}^{\circ} 49$ a $25 \mathrm{~km}$ del área de atención a los visitantes, hacia el este. Existe un proyecto para habilitar un sector de acampe de características agrestes en la Seccional Cerro Horqueta.

Alojamiento: No hay posibilidad de alojamiento dentro del AP. La opción más cercana es el Camping La Paloma o las localidades cercanas.

Prestadores de servicios turísticos y Guías: No hay prestadores de servicios turísticos ni guías habilitados para el área.

- Audio guía Fitz Roy-Jaramillo al Parque Nacional Bosques Petrificados: El material está pensado para un recorrido vehicular relatando historias de los sucesos de la Patagonia Rebelde y llegando hasta la Portada del MNBP. Este material es gratuito y agrega valor interpretativo a los viajes en vehículo.

- Ruta de la huelga de 1921: esta empresa ofrece dentro de sus productos, la excursión: Jaramillo- Bosques Petrificados- Gobernador Gregores Ruta 12.

Nuevos senderos y sitios de visita:

- Cerro Madre e Hija: Se prevé la habilitación de un sendero para ascender a este cerro con dificultad media/alta, y de aproximadamente 4 horas de duración (ida y vuelta).

- Miradores y sitios panorámicos: es necesario instalar miradores panorámicos en distintos puntos atractivos y algunos miradores temáticos puntuales.

Transporte: No existen medios de transporte público y regular de pasajeros para acceder al AP desde las localidades cercanas. El aeropuerto más cercano se encuentra en la ciudad de Comodoro Rivadavia a $310 \mathrm{~km}$.

\subsubsection{Estancias del Noreste de Santa Cruz: su patrimonio y localización}

En el trabajo de investigación plasmado en el libro "Estancias del Noreste de Santa Cruz, su historia y su patrimonio en la primera mitad del siglo XX" (Ibarroule, Sampaoli y Tagliorette, 2011) se detallan propiedades rurales en Zona Catastral de Cabo Blanco, en la provincia de Santa Cruz.

Esta zona muestra las características de la última etapa del proceso de ocupación que va desde 1915 a 1920 con unidades de producción pequeñas y medianas. Los lotes son cuadrados de 10.000 metros de lado, siguiendo un catastro absolutamente regular. 
Las autoras relevaron un total de 10 establecimientos rurales ${ }^{2}$ elegidos con el criterio de la accesibilidad, especialmente la mayor cercanía a rutas pavimentadas:

Estancia "Bahía Lángara" de los herederos de Ceferino Ardura.

Estancia "Buena Vista" de Isidro Izurrategui.

Estancia "Cerro Mesa" de Walter Kirn.

Estancia "El Cordón" de Isidro Izurrategui.

Estancia "Golondrinas" de la sucesión de Olaf Fjell (no incluida por su ubicación).

Estancia "La Consuelo" de José y Alicia Rivera.

Estancia "La Guanaca" de La Isla S.A.

Estancia "La Paulita" de Isidro Izurrategui.

Estancia "Las Rosas" de Carlos Hermoso e hijos.

Estancia "San Jorge" de Jorge Fratzscher y hermanos

\section{Características:}

En esa investigación se observa que todos los campos cuentan con aguas de vertientes, están atravesados por cañadones y sus tierras aceptan el pastoreo de ganado en grado medio pero no son aptas para la agricultura. En un $25 \%$ de los establecimientos de la zona, la explotación petrolera impide el desarrollo de la ganadería en el mediano plazo. Y, si bien la producción petrolera les ofrece importantes ingresos, implica instalaciones, tráfico intenso y, a veces, contaminación del suelo.

Las autoras encuentran que el carácter de las construcciones, es sencillo, funcional y adaptado al medio. Se utilizaba lo que la industrialización de la época ofrecía: chapas de zinc y madera. Sólo se diferencia el muro interno de las viviendas principales, donde se utilizó el "adobe con distintas fibras (de duraznillo por ejemplo) o de entramado denominado chorizo". Lo encuadran en arquitectura popular, es decir, arquitectura sin arquitectos, donde se aprende por imitación. Es una arquitectura espontánea, de acuerdo a las necesidades surgidas. El constructor yugoeslavo Mateo Barac es autor de muchas de las viviendas principales y de casi todos los bañaderos de cemento examinados.

Algunos propietarios reemplazaron las casas originales de chapa, por otras de piedra o de ladrillo. La vivienda principal de la estancia Bahía Lángara se destaca por los materiales en su construcción -piedra de una cantera del mismo campo- y por el valor estético que le imprimió su constructor, el ya mencionado Barac. Cuenta también con un importante patrimonio inmaterial constituido por la historia de vida del pionero dueño de la Estancia, Ceferino Ardura.

El valor de estas propiedades, si bien no puede basarse en lo estético como en los grandes latifundios del sur de la provincia, expresa las formas de vida en el pasado de valor simbólico para la zona rural del noreste de Santa Cruz.

Del relevamiento efectuado, concluyen que algunos establecimientos podrían comenzar con la visita de un día sin pernocte: como alternativa recreativa de las ciudades vecinas: Comodoro Rivadavia, Caleta Olivia, Puerto Deseado, etc. y otros podrían ofrecer alojamiento (por ej. Bahía Lángara, Las Rosas, La Consuelo). Además de los atractivos intrínsecos de cada una de ellas, existe la posibilidad de vincular los establecimientos mediante circuitos que combinen diferentes temáticas. Las autoras proponen: "Tras los pasos de Mateo Barac", "El camino de la huelga en el noreste", "La Lobería: la reutilización de sus materiales", "El trayecto de la lana", "La irrupción del petróleo".

\footnotetext{
${ }^{2}$ Los datos de dueños de Estancias están tomados de la publicación "Estancias del Noreste de Santa Cruz, su historia y su patrimonio en la primera mitad del siglo XX" (Ibarroule, Sampaoli y Tagliorette, 2011) y pueden haberse modificado en la actualidad.
} 
Localización de las estancias respecto del PNBPJ
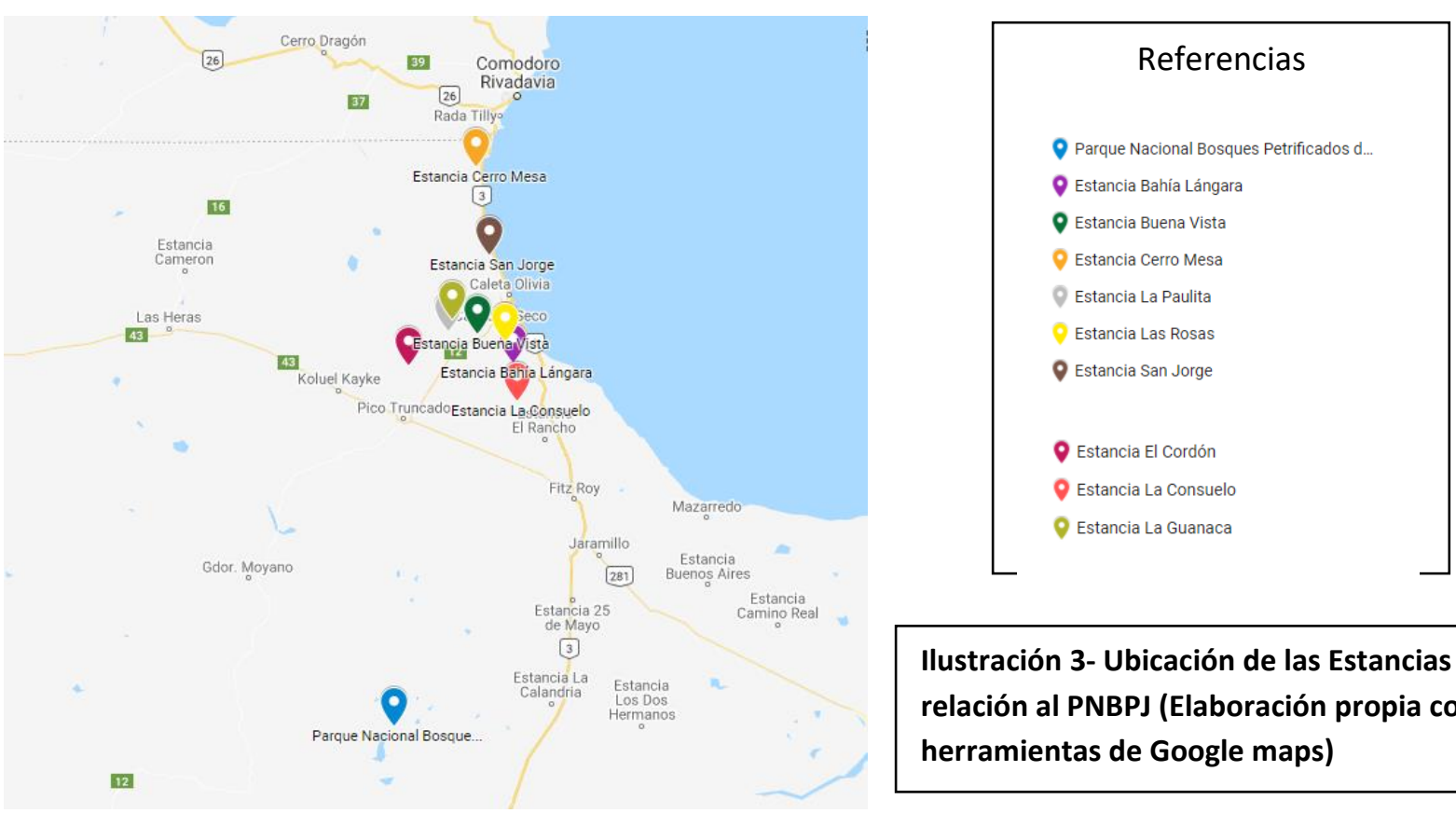

Ilustración 3- Ubicación de las Estancias en relación al PNBPJ (Elaboración propia con herramientas de Google maps)

\begin{tabular}{|l|l|c|c|c|}
\hline Estancia & Latitud & Longitud & $\begin{array}{c}\text { Distancia desde } \\
\text { Caleta Olivia }\end{array}$ & $\begin{array}{c}\text { Distancia al } \\
\text { PNBPJ }\end{array}$ \\
\hline Bahía Lángara & $-46^{\circ} 38^{\prime} 35^{\prime \prime}$ & $-67^{\circ} 30^{\prime} 0^{\prime \prime}$ & $45,3 \mathrm{~km}$ & $197 \mathrm{~km}$ \\
\hline Buena Vista & $-46^{\circ} 33^{\prime} 34^{\prime \prime}$ & $-67^{\circ} 38^{\prime} 49^{\prime \prime}$ & $18,3 \mathrm{~km}$ & $218 \mathrm{~km}$ \\
\hline Cerro Mesa & $-46^{\circ} 04^{\prime} 33^{\prime \prime}$ & $-67^{\circ} 39^{\prime} 13^{\prime \prime}$ & $42,4 \mathrm{~km}$ & $258 \mathrm{~km}$ \\
\hline El Cordón & $-46^{\circ} 39^{\prime} 00^{\prime \prime}$ & $-67^{\circ} 56^{\prime} 00^{\prime \prime}$ & $45,9 \mathrm{~km}$ & $228 \mathrm{~km}$ \\
\hline La Consuelo & $-46^{\circ} 45^{\prime} 00^{\prime \prime}$ & $-67^{\circ} 29^{\prime} 00^{\prime \prime}$ & $60,3 \mathrm{~km}$ & $186 \mathrm{~km}$ \\
\hline La Guanaca & $-46^{\circ} 31^{\prime} 00^{\prime \prime}$ & $-67^{\circ} 45^{\prime} 00^{\prime \prime}$ & $26,7 \mathrm{~km}$ & $227 \mathrm{~km}$ \\
\hline La Paulita & $-46^{\circ} 33^{\prime} 00^{\prime \prime}$ & $-67^{\circ} 46^{\prime} 00^{\prime \prime}$ & $28,0 \mathrm{~km}$ & $227 \mathrm{~km}$ \\
\hline Las Rosas & $-46^{\circ} 35^{\prime} 00^{\prime \prime}$ & $-67^{\circ} 32^{\prime} 00^{\prime \prime}$ & $26,6 \mathrm{~km}$ & $226 \mathrm{~km}$ \\
\hline San Jorge & $-46^{\circ} 20^{\prime} 00^{\prime \prime}$ & $-67^{\circ} 36^{\prime} 00^{\prime \prime}$ & $16,6 \mathrm{~km}$ & $232 \mathrm{~km}$ \\
\hline
\end{tabular}

Tabla 3- localización y distancia a las estancias (elaboración propia basado en información de Google Maps - Anexo 5)

Recursos culturales con potencial turístico presentes en las estancias

Las Estancias del noreste de la provincia de Santa Cruz poseen un patrimonio cultural material e inmaterial relevante que enriquece el conocimiento de la historia local y regional. Preservar, conservar o poner en valor sitios u objetos que pertenecen al patrimonio de una sociedad, no tiene como objeto sólo luchar contra la destrucción natural o el vandalismo, sino, también afirmar la identidad cultural de la región.

Teniendo en cuenta que se debe sumar el patrimonio inmaterial conformado por las costumbres, tradiciones y relatos referidos a estas estancias, se resumen a continuación los recursos culturales materiales con potencial turístico en cada una de ellas. 


\begin{tabular}{|c|c|c|c|c|}
\hline Estancia & Arquitectónico & Arqueológico & Paleontológico & Histórico \\
\hline $\begin{array}{l}\text { Bahía } \\
\text { Lángara }\end{array}$ & $\begin{array}{l}\text { Vivienda principal. } \\
\text { Arquitectura de tipo europeo, } \\
\text { de piedra. } \\
\text { Galpón de esquila (obra de } \\
\text { Barac). }\end{array}$ & $\begin{array}{lr}\text { Sitios } & \text { concheros, } \\
\text { concentraciones } \\
\text { de } r \text { artefactos } \\
\text { líticos, restos } \\
\text { óseos r } \\
\text { cerámicos, así } \\
\text { como entierros } \\
\text { humanos, en la } \\
\text { zona costera }\end{array}$ & & $\begin{array}{l}\text { Fotografías y libros } \\
\text { antiguos. } \\
\text { Trazado original de la } \mathrm{RN} \\
\text { 3, antigua ruta del correo }\end{array}$ \\
\hline Buena Vista & $\begin{array}{l}\text { La vivienda principal de } \\
\text { paredes y techo en chapas de } \\
\text { zinc con influencia británica, } \\
\text { del estilo de las que se } \\
\text { compraban en Inglaterra en } \\
1900 \text { y que luego se armaban } \\
\text { en la Patagonia }\end{array}$ & & & $\begin{array}{l}\text { El pozo donde se } \\
\text { descubrió petróleo en } \\
\text { Santa Cruz, se encuentra } \\
\text { en la estancia colindante } \\
\text { hacia el este. }\end{array}$ \\
\hline Cerro Mesa & \begin{tabular}{lcr}
\multicolumn{1}{l}{ Vivienda } & construida & con \\
ladrillos & importados & de \\
Hamburgo y también & de \\
origen nacional. & &
\end{tabular} & $\begin{array}{lr}\text { Sitios } & \text { concheros, } \\
\text { concentraciones } \\
\text { de r } & \text { artefactos } \\
\text { líticos, restos } \\
\text { óseos, sobre la } \\
\text { costa }\end{array}$ & & $\begin{array}{l}\text { Depósito levantado con las } \\
\text { chapas recicladas del } \\
\text { establecimiento r de } \\
\text { faenamiento de lobos } \\
\text { marinos llamado } L a \\
\text { Lobería -que funcionara en } \\
\text { la costa entre } 1923 \text { y } 1933\end{array}$ \\
\hline El Cordón & $\begin{array}{l}\text { Vivienda principal, construida } \\
\text { en } 1934 \text { por un constructor } \\
\text { llamado Valdebenito. Galpón } \\
\text { de esquila, levantado en } 1926\end{array}$ & & & $\begin{array}{l}\text { Restos del campamento } \\
\text { petrolero conocido como } \\
\text { Perro Negro de los años } \\
\text { 60, de la empresa italiana } \\
\text { Saipem }\end{array}$ \\
\hline La Consuelo & $\begin{array}{l}\text { El garage-despensa, la } \\
\text { habitación de don Mateo, la } \\
\text { vivienda principal, la usina- } \\
\text { carnicería, el galpón de } \\
\text { esquila y el gallinero, con } \\
\text { paredes de ladrillo y techos de } \\
\text { chapa, construidas por Mateo } \\
\text { Barac e inauguradas en } 1958\end{array}$ & & & $\begin{array}{l}\text { Auto transformado en } \\
\text { camioneta por su } \\
\text { propietario, Mateo Barac }\end{array}$ \\
\hline La Guanaca & $\begin{array}{l}\text { Las construcciones son obra } \\
\text { de Arturo Phillips. Los muros } \\
\text { son de adobe tipo rama } \\
\text { embarrada-, los techos de zinc } \\
\text { y la carpintería de madera. }\end{array}$ & & & \\
\hline La Paulita & $\begin{array}{l}\text { En } 1927 \text { Mateo Barac inició } \\
\text { la obra correspondiente a la } \\
\text { vivienda principal con muros } \\
\text { de ladrillo y techo de chapas } \\
\text { de zinc. Galpón de esquila de } \\
1914\end{array}$ & & & \\
\hline Las Rosas & $\begin{array}{l}\text { Casa principal de adobe y } \\
\text { chapa (anexos de ladrillo, } \\
\text { mosaico calcáreo y madera.). } \\
\text { Galpón de esquila re- } \\
\text { construido con bloques y } \\
\text { pisos de cemento. }\end{array}$ & $\begin{array}{l}\text { A } 5 \mathrm{~km} \text {. hay un } \\
\text { picadero. }\end{array}$ & $\begin{array}{l}\text { Depósitos naturales } \\
\text { de ostrones } \\
\text { precámbricos en las } \\
\text { laderas de los } \\
\text { cerros.Vestigios de } \\
\text { las ingresiones } \\
\text { marinas con forma } \\
\text { de restingas. }\end{array}$ & $\begin{array}{l}\text { El lugar donde se asienta } \\
\text { el casco actual, era un } \\
\text { asentamiento indígena, ya } \\
\text { que se han encontrado } \\
\text { fogones y flechas. }\end{array}$ \\
\hline San Jorge & $\begin{array}{l}\text { El casco viejo de la década } \\
\text { del '30, con vista al mar. } \\
\text { Excelente bañadero y } \\
\text { secaderos de cemento } \\
\text { realizado por Mateo Barac }\end{array}$ & & & Cementerio familiar \\
\hline
\end{tabular}

Tabla 4-Recursos culturales materiales con potencial turístico en Estancias del NE de Santa Cruz (Elaboración propia. Fuentes Ibarroule et al., 2011; Zubimendi et al., 2014) 


\subsection{Discusión}

\subsubsection{El PNBPJ como atractivo turístico}

Por ser el yacimiento paleontológico de su tipo más importante del país y uno de los mayores del mundo, por la cantidad, tamaño y calidad de la conservación de los restos vegetales que en él se resguarda, no se pondría en duda ver al PNBPJ como un atractivo turístico de jerarquía. Pero, si se considera la viabilidad turística, tal como la plantea Prats (2011), no se lo podría incluir en ninguna de las tres categorías. Este autor califica como turísticamente viables, los recursos culturales que:

- Son capaces de atraer por sí mismos una importante cantidad de visitantes.

- Con una capacidad de atracción menor, pero se hallan emplazados dentro o cerca de entornos metropolitanos lo suficientemente grandes.

- Se hallan ubicados en destinos turísticos consolidados, maduros o de éxito, independientemente de su capacidad intrínseca de atracción turística.

Esto se ve reflejado en el número de visitantes que recibe anualmente, sólo el 0,5\% de la cantidad que recibe el PN Los Glaciares. Es notorio también el hecho de que, siendo la demanda turística en la provincia repartida en 50/50 entre residentes y extranjeros, las visitas de los no residentes al PNBPJ sólo representan el $24 \%$ de ellas. (Tabla 2)

Pero, a su vez, el mismo autor (Prats, 1997) resalta que el patrimonio posee algunas virtudes que lo hacen especialmente atrayente: es gratis, no está sujeto a la estacionalidad de otras ofertas, y "le otorga al destino turístico distinción y respetabilidad".

Además se puede prever un cambio en el perfil del turista pos-pandemia. Como producto del temor a lo desconocido, modificará sus preferencias hacia territorios locales, en los cuales espera encontrar mayor seguridad, con factores culturales, económicos y sanitarios conocidos, como así también se inclinará a ambientes naturales poco antropizados. A eso se le suma una tendencia más estructural vinculada al aumento de las preocupaciones medioambientales.

Otro aspecto a considerar es su localización, accesibilidad y servicios ofrecidos. Ingresando por RN 3 debemos recorrer $50 \mathrm{~km}$ de ripio y la localidad más cercana para cargar combustible es Fitz Roy, a 140 km. Esto sumado a la imposibilidad de pernoctar en el lugar, o, ni siquiera tener espacio para compartir un alimento, hacen disminuir su capacidad de atraer turistas.

\subsubsection{Aptitud o vocación turística de las Estancias del noreste de Santa Cruz}

Como se ha planteado, para la década de 1940, la ganadería continuaba siendo la producción principal en el territorio, a pesar del estancamiento. Pero, para esa misma época, comienza la explotación minera que desplazaría lentamente la actividad ganadera para consolidarse entre 1960 y 1980. Esto ha generado un importante cambio, modificando el paisaje, eliminando alambrados e introduciendo elementos del Patrimonio industrial, como torres de perforación y equipos de bombeo.

Como se dijo con anterioridad, en un $25 \%$ de los establecimientos de la zona, la explotación petrolera impide el desarrollo de la ganadería en el mediano plazo. A cambio de ello, les ofrece importantes ingresos.

Pero esta actividad produce diversos efectos en el medio ambiente, desde la contaminación química (por derrames), sonora (por el funcionamiento de las máquinas) y visual; hasta erosión y cambios en la flora y fauna, por el tránsito de vehículos y movimientos de suelos. Esto se agrega a los procesos de desertificación como consecuencia del sobre pastoreo en otras épocas.

Abrir las puertas al Turismo, les permitiría la incorporación de una actividad económica ambientalmente más sustentable y también diversificar las fuentes de ingresos, y, tal vez, mejorar las condiciones de los campos, respecto de la desertificación. 
Aquellas estancias que pudieran ofrecer alojamiento incrementarían la oferta en la región, teniendo en cuenta que, como señalamos, las estadísticas indican que el $72 \%$ de las plazas se ubican en El Calafate, El Chaltén y Río Gallegos. Sumado a esto, contarían con la competencia de sólo dos establecimientos rurales turísticos en la zona (Tabla 1). Las estancias que estarían en condiciones de ofrecer alojamiento serían:

$\checkmark$ Bahía Lángara

$\checkmark$ Las Rosas

$\checkmark$ La Consuelo

Analizando su potencialidad para incorporarlas a un producto turístico relacionado con el PNBPJ, podemos observar en su localización que las más cercanas son:

- La Consuelo a $186 \mathrm{~km}$

- Bahía Lángara a 197 km

- Buena Vista a $218 \mathrm{~km}$.

En cuanto a los recursos patrimoniales con posibilidades turísticas, tres de ellas poseen sitios arqueológicos y/o paleontológicos que podrían relacionarse con la visita al PNBPJ:

$>$ Bahía Lángara

$>$ Cerro Mesa

$>$ Las Rosas

En cuanto a la predisposición, se debe tener en cuenta que al explorar el conocimiento y las actitudes de los ganaderos hacia la incorporación de otras actividades económicas, como es el caso del Turismo, la mayoría de los encuestados muestran su disposición para realizar inversiones en sus establecimientos para desarrollar actividades alternativas, pero reconocen que necesitan ayuda. También la mayoría afirmó no poseer infraestructura para alojar y atender turistas y carecer de conocimientos básicos para atención a los mismos. Otro aspecto a considerar, como plantean Samapaoli et al. (2018), es una insuficiente valoración turística del patrimonio cultural que se observa en las comunidades locales y autoridades, y que puede verse también reflejada en los propietarios de las estancias.

\subsubsection{Posibilidades de aprovechamiento turístico}

Como se ha planteado, dentro del Turismo rural, la Patagonia presenta ventajas comparativas, que basadas en su patrimonio natural y cultural, unen el tardío poblamiento con un paisaje poco antropizado (en particular en la zona noreste de Santa Cruz) capaz de generar productos con alto valor agregado.

Pensando en la categoría de Paisaje Cultural, si se incluyen las estancias y el PNBPJ, se podría hablar de un Paisaje Evolutivo conformado por lo Histórico Vernáculo, porque ha evolucionado con el uso de la gente y lo Etnográfico, con los diversos elementos naturales y culturales que sus habitantes reconocen como recursos patrimoniales. En el caso del PNBPJ, el paisaje se fue "enculturando" a través de las prácticas sociales y simbólicas. Por ello, los rasgos naturales del paisaje se apropian simbólicamente y se vuelven parte del mundo cultural.

Este paisaje incluye los yacimientos paleontológicos indisociables del entorno geológicopaisajístico en los que se encuentran, y las distintas formas de interacción con el entorno, desde los cazadores recolectores hasta la instalación de los establecimientos ganaderos a comienzos del XX.

Una recorrida por este paisaje relata los cambios drásticos que sufrió el ambiente, a través de la historia de la Tierra y los cambios posteriores, introducidos por el hombre. Así, esta perspectiva de caracterización de los paisajes culturales o históricos considera todos los aspectos naturales y culturales, antiguos y modernos. 
Chan (2014) indica que un circuito es la base para elaborar desde un producto simple, como una visita guiada, hasta algo más complejo, como un paquete turístico; y brinda el armazón físico sobre el cual se van a ir incorporando servicios y actividades.

Al pensar en un circuito que abarque alguna o varias estancias y el PNBPJ, se habla de uno temático. Se propone como título: "Cambia, todo cambia: Santa Cruz, entre fósiles y ovejas". Sus atractivos principales están basados en el patrimonio histórico, arqueológico y paleontológico y, como atractivos complementarios, la gastronomía y actividades rurales, sin olvidar los atractivos de entorno, con puntos panorámicos.

En el análisis realizado sobre las Estancias estudiadas, es Bahía Lángara la que cumple con los tres requisitos: mayor cercanía al PNBPJ, posibilidad de dar alojamiento y recursos patrimoniales históricos y arqueológicos, que permitiría interpretar el paisaje y sus cambios.

Por las distancias a recorrer entre la localidad de Caleta Olivia, el PNBPJ y la Estancia, debería pensarse en un producto de al menos 2 días/1 noche.

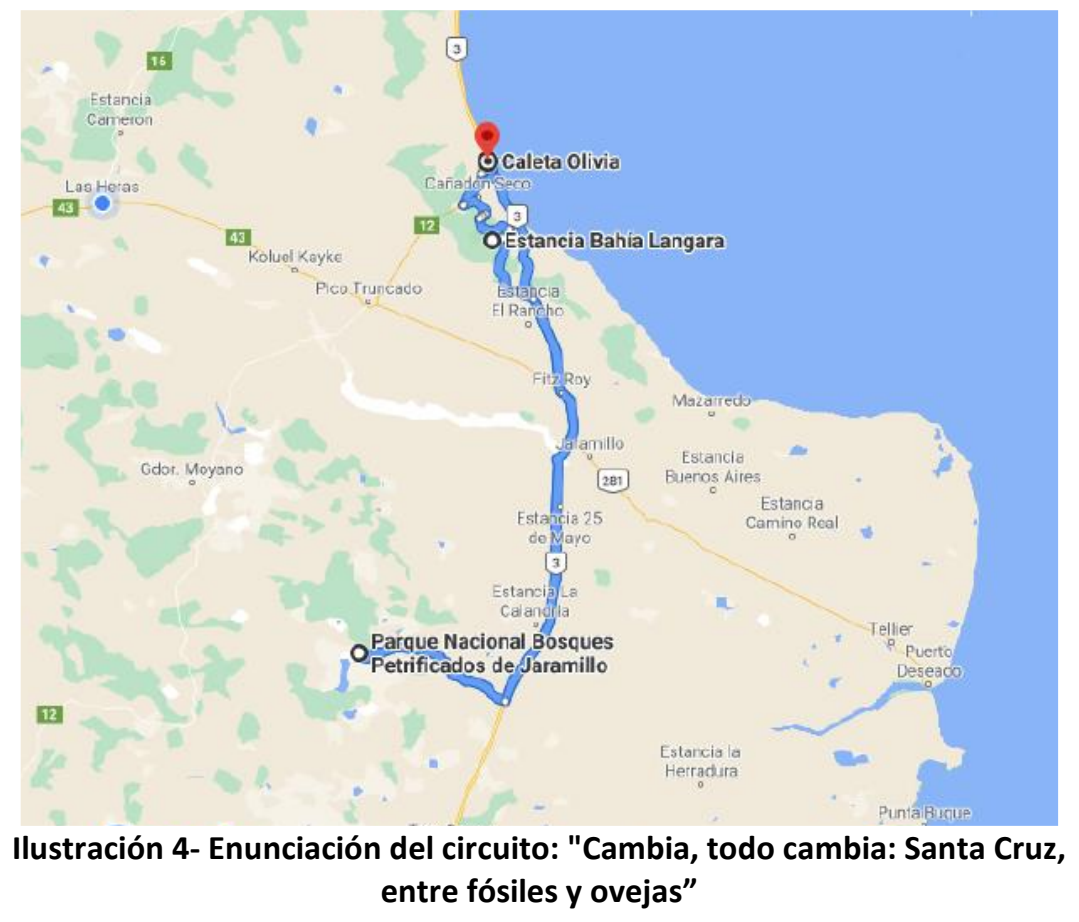

Exceptuando la Estancia Cerro Mesa, por su ubicación, el circuito podría incorporar a las otras estancias analizadas (Las Rosas, Bella Vista o La Consuelo). También podría incluir más de una si el producto abarca más de una noche de pernocte.

A partir del circuito enunciado se puede pensar el itinerario, consignando los centros base, todos los atractivos que se visitan o recorren, los servicios incluidos, los días y horas en que se desarrollarán las actividades, etc.

\section{CONCLUSIONES}

La provincia de Santa Cruz, con su extenso territorio, ofrece innumerables recursos turísticos tanto naturales como culturales. Sin embargo, cuando se analizan los datos estadísticos, se observa una concentración de servicios y actividades turísticas en el sur de la provincia, que se correlaciona con la información de la demanda turística.

La región noreste muestra un paisaje poco antropizado y un rico patrimonio natural y cultural, producto de distintas formas de interacción con el entorno, desde los cazadores recolectores, hace 12.000 años, hasta la instalación de los establecimientos ganaderos a comienzos del XX. 
Más tarde el auge de la lana dejó su lugar a la explotación petrolera, y este paisaje ha ido cambiando junto con las actividades y los actores sociales; además se sabe que esta última actividad produce diversos efectos en el medio ambiente: contaminación química, sonora y visual, erosión y cambios en la flora y fauna; sumado a los procesos de desertificación previos.

Al pensar en una propuesta sustentable para un circuito turístico que integre estancias del NE de la provincia de Santa Cruz y el PNBPJ, se buscó un desarrollo equilibrado desde los puntos de vista social y económico y en su interacción con el ambiente.

La apertura de estas Estancias al Turismo implica, de hecho, un beneficio para el medio ambiente, al ser una actividad no contaminante, que, a su vez, requiere el ejercicio de un Turismo Responsable, de cuidado y protección del patrimonio natural y cultural.

Desde el punto de vista social, la puesta en valor y la interpretación adecuada de los recursos patrimoniales favorecerá el sentimiento de pertenencia al lugar, recuperará la "memoria colectiva", colaborando en fortalecer la identidad cultural y la resiliencia.

El desarrollo de estos productos, como recursos económicos, puede ser una oportunidad para ampliar la oferta turística presentada por empresas de Caleta Olivia o Comodoro Rivadavia, como también incrementar el número de plazas de alojamiento en esta región. También beneficiaría económicamente a las estancias involucradas, diversificando las fuentes de ingresos y generaría nuevos empleos.

La puesta en valor del patrimonio arquitectónico e histórico de las Estancias, respetando la autenticidad, y el acatamiento de las normas de protección del patrimonio arqueológico y paleontológico contribuirán a la sustentabilidad del emprendimiento, permitiendo el uso de estos recursos por las futuras generaciones. Asimismo, su temática atemporal y la posibilidad de concretarlo en cualquier época del año, aporta a la sostenibilidad.

Después de investigar la aptitud turística de las Estancias del NE de Santa Cruz y las reales posibilidades de aprovechamiento del PNBPJ, se propone un nuevo circuito cultural, al cual se lo denomina: "Cambia, todo cambia: Santa Cruz, entre fósiles y ovejas", que relata los cambios drásticos que sufrió el ambiente, a través de la historia de la Tierra y los cambios posteriores, introducidos por el hombre.

Se encuentra, entonces, que es viable este circuito turístico, que reúne el turismo rural y paleontológico, recupera un Patrimonio Rural que enriquece la historia local y regional y aporta a la difusión de un yacimiento paleontológico de interés mundial. Este circuito puede ser la base de distintos productos que amplíen la oferta turística en esta zona de la provincia, beneficiando a las comunidades involucradas.

\section{RECOMENDACIONES}

\subsection{Para la protección de los recursos}

$\checkmark$ Propiciar que las intervenciones para la restauración, refuncionalización y puesta en valor del patrimonio histórico y arquitectónico en los establecimientos rurales sean respetuosas de los valores y características originales de la propiedad.

$\checkmark$ Solicitar asesoramiento profesional para la presentación e interpretación de los recursos paleontológicos y/o arqueológicos ubicados en las Estancias.

\subsection{Para ampliar y mejorar la oferta turística}

$\checkmark$ Implementar iniciativas que apoyen económica y técnicamente a los ganaderos que estén dispuestos a abrir sus puertas al turismo, apostando a actividades sustentables en los establecimientos ganaderos en el NE de Santa Cruz.

$\checkmark$ Ofrecer capacitación del recurso Humano necesario para la atención a turistas. 
$\checkmark \quad$ Mejorar la calidad de la visita al PNBPJ, con un centro de visitantes adecuado, una atrayente muestra interpretativa y cartelería en el sendero "huellas del pasado" (como está previsto en el Plan de Manejo)

\subsection{Para mejorar la accesibilidad}

$\checkmark$ Mantenimiento vial en carreteras de acceso a las Estancias en el Noreste santacruceño y al PNBPJ.

$\checkmark \quad$ Mejorar la señalización en rutas, indicando la cercanía de atractivos turísticos.

\subsection{Generales}

$\checkmark$ Difundir la importancia y valor de los Bosques Petrificados de Jaramillo en las localidades cercanas a través de acciones educativas formales e informales.

$\checkmark \quad$ Fortalecer el turismo interno de cercanía, promoviendo la visita de turistas y excursionistas de localidades y provincias vecinas, durante los fines de semana.

$\checkmark$ Ampliar la promoción oficial de productos turísticos de la zona norte de la Provincia.

\section{AGRADECIMIENTOS}

Al equipo de investigación que me recibió como becaria y me permite crecer día a día y, en especial, a la Mg. Patricia Sampaoli por su apoyo, y también, sus correcciones y sugerencias.

\section{ANEXOS}

\section{Anexo 1: Demanda Anual}

(1) Promedio 2012-2019;(2)Promedio 2018/19

\begin{tabular}{|c|c|c|c|}
\hline \multicolumn{4}{|c|}{ CANTIDAD DE TURISTAS ANUALES } \\
\hline & Turistas & $\begin{array}{c}\text { Part. \% en } \\
\text { Santa Cruz }\end{array}$ & $\begin{array}{c}\text { Part. \% en } \\
\text { Total País }\end{array}$ \\
\hline TURISTAS RESIDENTES (1) & 374.884 & $50 \%$ & $1 \%$ \\
\hline TURISTAS EXTRANJEROS (2) & 381.034 & $50 \%$ & $5 \%$ \\
\hline TOTAL DE TURISTAS & 755.918 & $100 \%$ & $1 \%$ \\
\hline
\end{tabular}

Fuente: DNMyE en base a datos de la EVyTH, la ETI-Indec y la Dirección Nacional de Migraciones

Anexo 2: Estacionalidad- Porcentaje de turistas por trimestre en Santa Cruz. Promedios 2012-2019

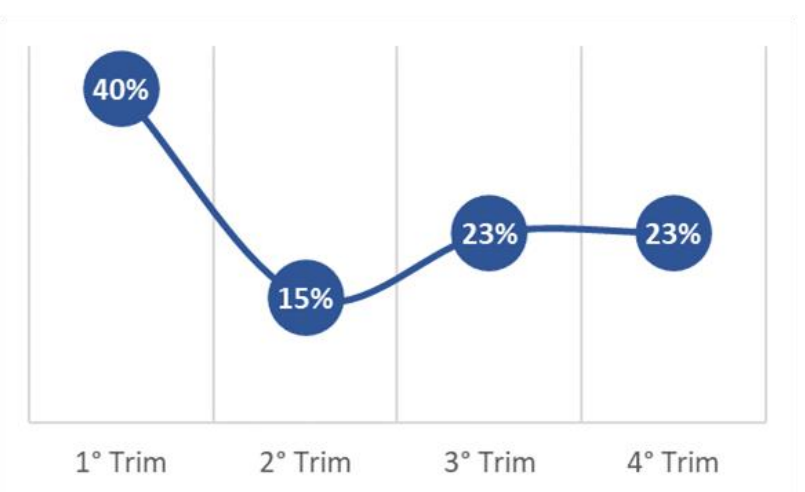

Fuente: DNMyE en base a datos de la EVyTH, la ETI-Indec y la Dirección Nacional de Migraciones 


\section{Anexo 3: Padrón de Alojamiento Colectivo 2018}

Participación sobre el total de plazas en las principales localidades. Año 2018.

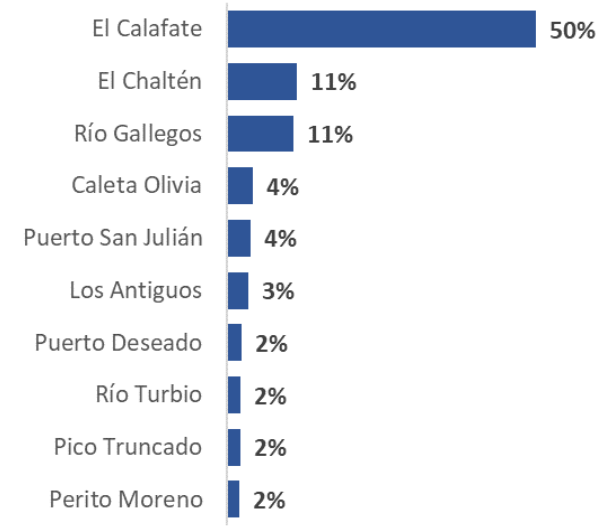

Fuente: DNMyE en base al Padrón Único Nacional de Alojamiento (PUNA).

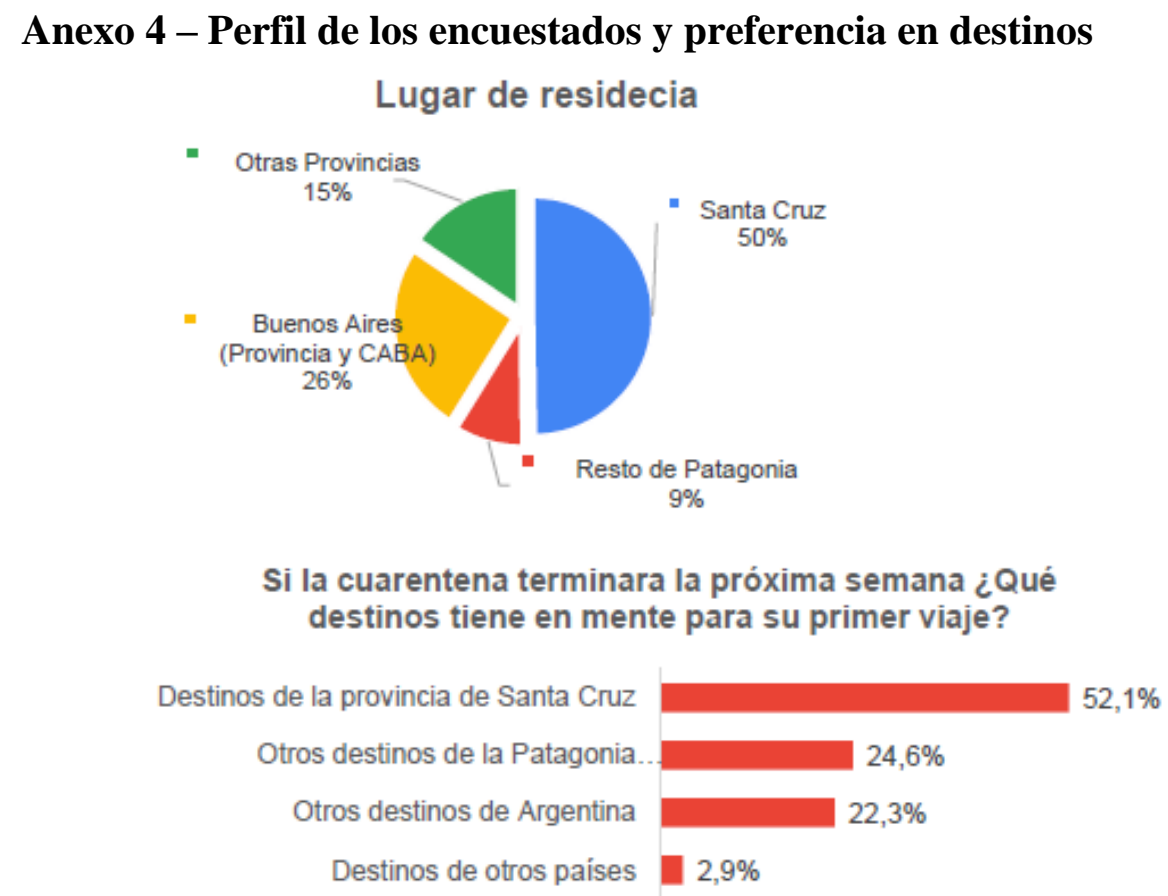

Fuente: Encuesta de expectativas de viajes por Santa Cruz. (OETuSC) 


\section{Anexo 5: Localización Estancias del NE de Santa Cruz y su distancia a Caleta Olivia y al} PNBPJ

Estancia Bahía Lángara

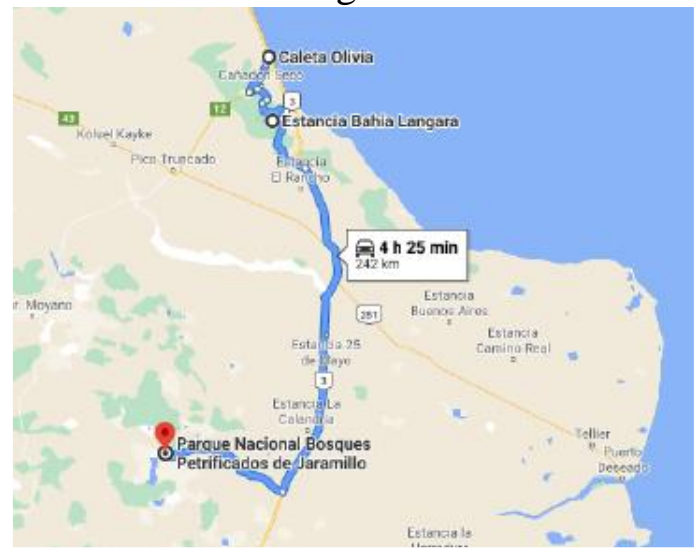

Estancia Cerro Mesa

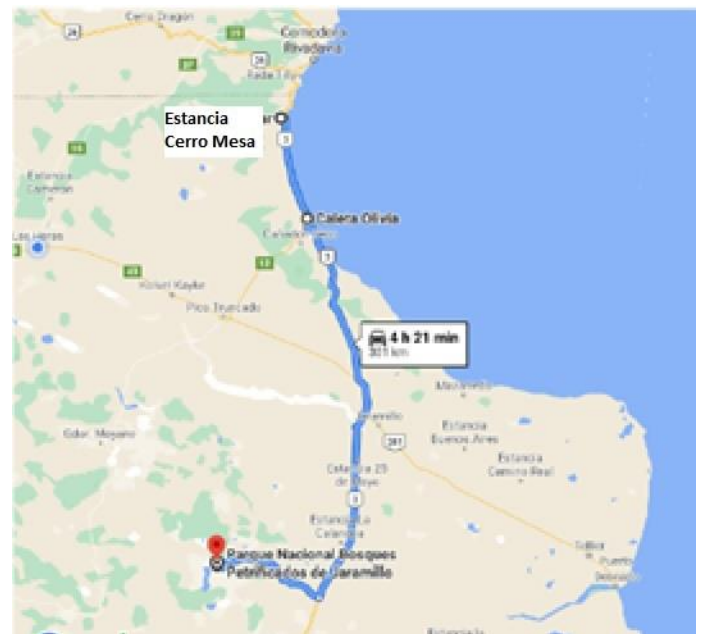

Estancia La Consuelo

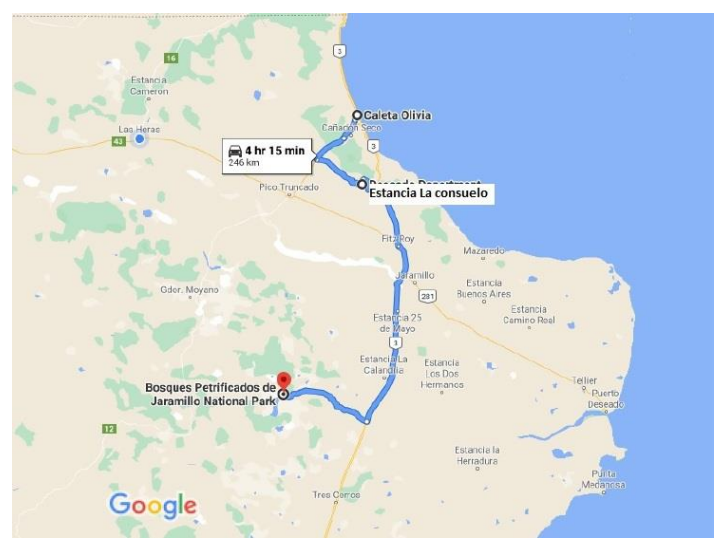

\author{
Estancia Buena Vista
}

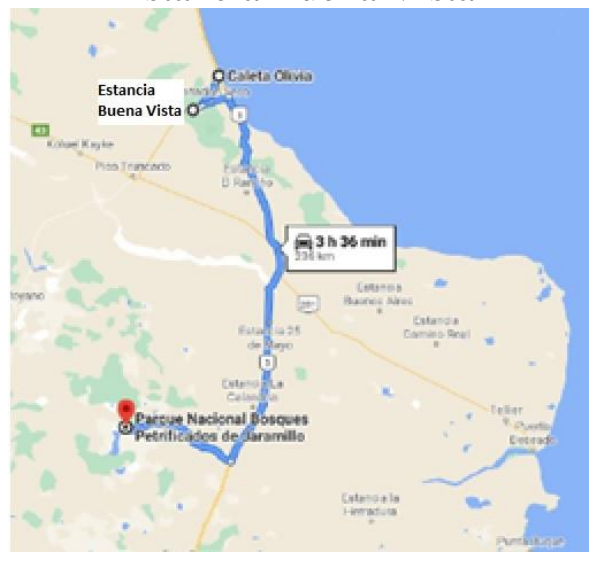

Estancia El Cordón

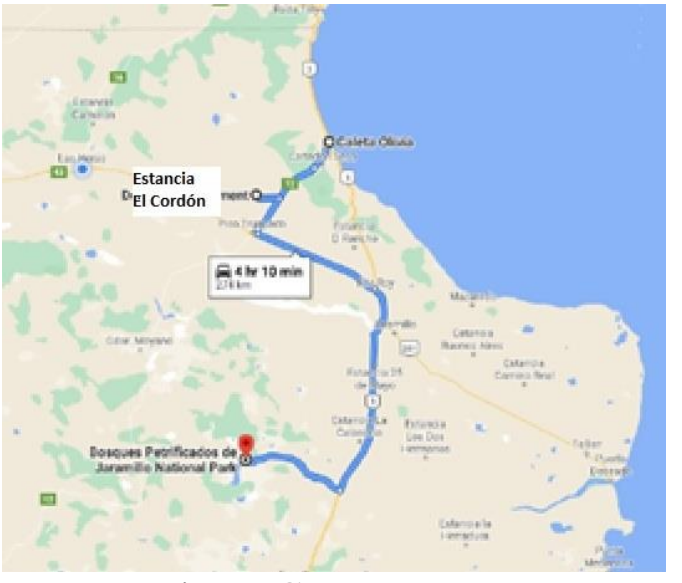

Estancia La Guanaca

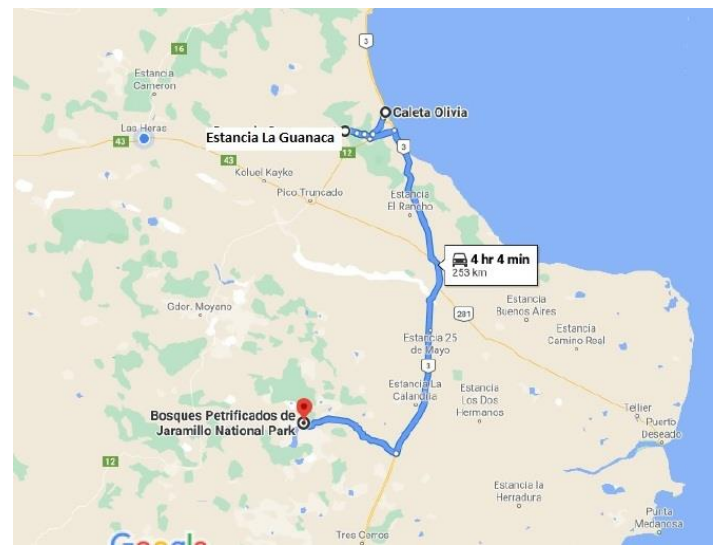


Estancia La Paulita

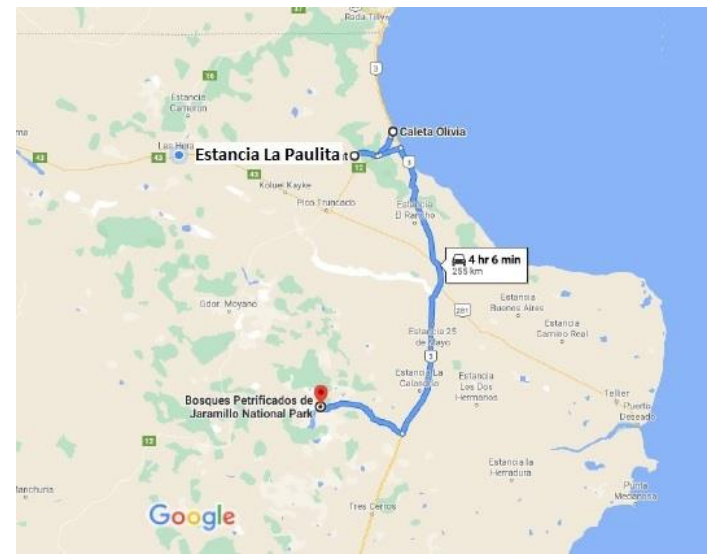

Estancia San Jorge

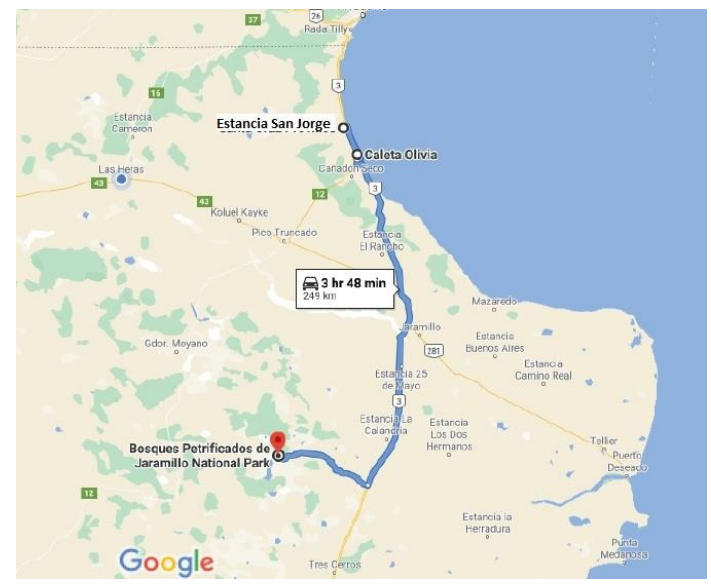

Estancia Las Rosas

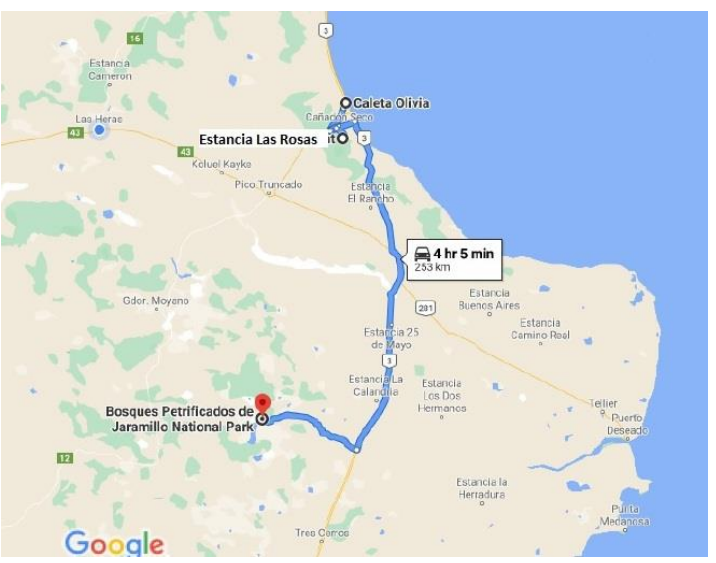

\section{REFERENCIAS BIBLIOGRÁFICAS}

Academia Nacional de Ciencias (2019) Todos nuestros académicos: Anselmo Windhausen. www.anc-argentina.org.ar

Administración de Parques Nacionales (2018) Plan de gestión Parque Nacional Bosques Petrificados de Jaramillo y Monumento Natural Bosques Petrificados.

ALONSO, J. A. (1998) A orillas del Ferro-Carril. Instituto Salesiano de Artes Gráficas. Buenos Aires.

ARCUCCI, A y PRADO, J (coord.) (2010) Mesa redonda de Patrimonio en las XXV Jornadas Argentinas de Paleontología de Vertebrados. San Luis.

ARIAS INCOLLÁ, M. N. (1999) "El paisaje Cultural: Una nueva categoría del Patrimonio Mundial" en Paisajes Culturales. Un enfoque para la salvaguarda del patrimonio. Buenos Aires:Suma Copy.

BALLART HERNÁNDEZ, J y TRESERRAS, J. (2008). Gestión del patrimonio cultural. Barcelona, Sp: Editorial Ariel.

BALLART, J. (1997). El patrimonio histórico y arqueológico: valor y uso. Barcelona: Ariel. 
BORRERO, L. A. (2009) El poblamiento de Santa Cruz. En Estado Actual de las Investigaciones realizadas sobre Patrimonio Cultural en Santa Cruz. Editorial Patrimonio Cultural. Provincia de Santa Cruz. Río Gallegos; (pp. 125 - 130).

CARO, J., ZAPATA, S. C., ZANÓN, J. I., RODRÍGUEZ, A. y TRAVAINI, A. (2017) Ganadería ovina y usos alternativos del suelo en la Patagonia austral, Argentina. Multequina, $N^{\circ} 26$ pp. 33-50. Instituto Argentino de Investigaciones de las Zonas Áridas Mendoza, Argentina.

CARRERAS DOALlO, X. (2012) Parques Nacionales y peronismo histórico. La Patria mediante la naturaleza. Estudios y Perspectivas en Turismo. Vol 21 (2012) pp. 1328 -1335. Universidad Nacional de Quilmes. Bernal. Argentina

CASTILLO, C., CASTILlO, J. COELlO, J. MARTIN, E. MARTÍN, M. y MÉNDEZ, A. (1999) La tutela del Patrimonio Paleontológico en Canarias. Coloquios de Paleontología, $\mathrm{N}^{\mathrm{o}}$ 50, (pp. 9-22)

CHAN, N (2014). Circuitos Turísticos: programación y cotización. España: Ediciones Turísticas

CISELLI, G (2009) Las Heras. Santa Cruz. Argentina. YPF S.A. Buenos Aires.

CORTIJO, J. (2013). Paisaje y patrimonio rural: Las “mieses” en Valdáliga, Herrerías y Rionansa. Universidad de Cantabria. Recuperado de https://repositorio.unican.es/ xmlui/handle/10902/3892

CÚNEO, N. R. y PANZA, J. L. (2008). Sitios de Interés Geológico de la República Argentina. CSIGA (Ed.) Instituto de Geología y Recursos Minerales. Servicio Geológico Minero Argentino, Anales 46, II, 461 págs., Buenos Aires.

DÍAZ MARTÍNEZ, E., CARCAVILLA, L. y GARCÍA CORTEZ, A. (2013) Los fósiles son elementos geológicos y el patrimonio paleontológico es un tipo de Patrimonio Natural. En Vegas, J, Salazar, A., Díaz Martínez, E. y Marchán, C. (eds.). Patrimonio geológico, un recurso para el desarrollo. Cuadernos del Museo Geominero, $\mathrm{n}^{\mathbf{0}}$ 15. Madrid: Instituto Geológico y Minero de España

ENDERE, M. L. y PRADO, J. L. (2009). Criterios de selección, valorización y zonificación de yacimientos arqueológicos y paleontológicos. En Patrimonio, Ciencia y Comunidad, (pp.49-66).

ERCOLANI, P. y SEGUÍ LLINÁS, M. (2011) Turismo Rural en la Patagonia Argentina. Oportunidades y desafíos. Universidad Carlos III de Madrid

GARCÍA LÓPEZ, A (2008) Patrimonio Cultural: diferentes perspectivas. ARQUEOWEB. Revista Sobre Arqueología en internet 9(2)

GUASTAVINO, M., ROZENBLUM, C. y TRÍMBOLI, G. (s/f) El Turismo Rural en el INTA, estrategias y experiencias para el trabajo en extensión. Instituto Nacional de Tecnología Agropecuaria. Argentina

IBARROULE, A., SAMPAOLI, P. y TAGLIORETTE, A. (2011). Estancias del NE de la Provincia de Santa Cruz. Su Historia y su Patrimonio en la primera mitad del siglo XX. Río Gallegos: Editorial Universidad Nacional de la Patagonia Austral. UNPAEdita.

JENSEN, M. BOUTEILLER, M.S. y ZEINSTEGER, E. (2009) El patrimonio arquitectónico de la Estancias de Tierra del Fuego como recurso turístico. En: Turismo Rural en América Latina, revista digital $N^{\circ} 3$. Centro de Investigaciones y Estudios Turísticos. Buenos Aires.

MAGNIN, L y BLANCO, R (2019) Primera noticia de arte Rupestre en el Parque Nacional Bosques Petrificados de Jaramillo (Santa Cruz, Argentina). Relaciones de la Sociedad Argentina de Antropología XLIV (2), julio-diciembre 2019: 341-348 
MAGNIN, L., MIOTTI, L. y HERMO, D. (2018) Perspectivas del estudio arqueológico del paisaje en el Parque Nacional Bosques Petrificados de Jaramillo (Santa Cruz, Argentina). Revista del Museo de La Plata. 3 (1) 132- 147. Universidad Nacional de La Plata. Facultad de Ciencias Naturales y Museo.

Ministerio de Medio Ambiente (2005) Guía Visual Parques Nacionales de la Argentina. Buenos Aires: TIRICA Ediciones de la Naturaleza.

MIOTTI, L y SALEMME, M (2004) Poblamiento, movilidad y territorios entre las sociedades cazadoras-recolectoras de Patagonia. Complutum, Vol. 15: 177-206

MIOTTI, L. L., HERMO, D. y CARDEN, N. (2009) Piedra Museo, una ventana abierta hacia los cazadores-recolectores que colonizaron la Meseta Central de Santa Cruz durante finales de la era glacial. Estado Actual de las Investigaciones realizadas sobre Patrimonio Cultural en Santa Cruz. Año: 2009; p. 173 - 184. Editorial Patrimonio Cultural. Provincia de Santa Cruz. Río Gallegos.

MONFORT MIR, V. (2010) El encuentro de los intangibles con el turismo sostenible. En Boto Alvarez L. (comp) Turismo y Gobierno: la construcción de una política interdisciplinaria. $1^{\circ}$ ed. Buenos Aires: Fundación Proturismo.

PASTOR-ALFONSO, M. J. (2003) El patrimonio cultural como opción turística. Horizontes Antropológicos 9 (20), 97-115.

PEZZONI, M. (2014) Turismo Rural, su tratamiento a través de la normativa. Observatorio de Derecho del Turismo. Facultad de Derecho UBA. Buenos Aires.

PISANO, M. F. y HALPERN, K. (2009). Los que aquí vivieron. Paleontología argentina. 1a ed. - Buenos Aires: Fundación de Historia Natural Félix de Azara: Ministerio de Educación de la Nación.

PRATS, L. (1997) “Antropología y patrimonio”. Barcelona:Ariel SA

PRATS, L. (2000) El concepto de patrimonio cultural. Cuadernos de Antropología Social 11: 115-136.

PRATS, L. (2003). Patrimonio + Turismo $=$ ¿Desarrollo?. PASOS: Revista de Turismo y Patrimonio Cultural. 1, (2), 127-136

PRATS, L. (2011) "Viabilidad turística del patrimonio", Pasos. Revista de turismo y patrimonio cultural. 9, (2), 249-264

RIVERA-HERNÁNDEZ, J. E., BLANCO-OROZCO, N. V., ALCÁNTARA-SALINAS, G., HOUBRON, E. P., y PÉREZ-SATO, J. A. (2017). ¿Desarrollo sostenible o sustentable? La controversia de un concepto. Posgrado Y Sociedad. Revista Electrónica, 15(1), 57-67.

ROMÁN, M. F. y CICCOLELlA, M. (2009) Turismo Rural en la Argentina Concepto, situación y perspectivas. Buenos Aires: IICA.

SAMPAOLI, P, TAGLIORETTE, A, REYNOSO, E, ZUBIMENDI, M. A., CASTRO, M. A., CHACOMA QUINTANA, G. (2018) Alumbrando el camino de los silencios 2: nuevas miradas a la puesta en valor del rescate del Patrimonio Cultural de la provincia de Santa Cruz - 1a ed . - Río Gallegos: Universidad Nacional de la Patagonia Austral.

SCOVENNA, L. (2000) De Turismo y turistas. En: Godoy, C (Ed). El Gran libro de Santa Cruz. Alfa Centro Literario, Madrid, España.

SHLÜTER, R. (2003) El Turismo en Argentina, del balneario al campo. Centro de Investigaciones y estudios turísticos. $2^{\circ}$ Edición

SPEGAZZINI, C. (1924) Coniferales fósiles patagónicas. Anales de la Sociedad Científica Argentina. Enero-abril 1924- Entregas I-IV (p. 433- 447)

SUERO, T (1959) Los Bosques petrificados de la Patagonia. Revista de la Universidad $N^{\circ}$ 7. Enero - abril, 1959. Universidad Nacional de La Plata. 
TRONCOSO, C. y ALMIRÓN, A. V. (2005) Turismo y Patrimonio. Hacia una relectura de sus relaciones. En Aportes y Transferencias 9 ( 1) 56-74.

VIZCAÍNO, S., BARGO, M. S. y FERNICOLA, J. (2013). Expediciones paleontológicas durante los Siglos XIX y XX a la Formación Santa Cruz (Mioceno Inferior, Patagonia) y destino de los fósiles. III Congreso Argentino de Historia de la Geología, Actas.

ZAMORA ACOSTA, E. (2011) Sobre patrimonio y desarrollo. Aproximación al concepto de patrimonio cultural y su utilización en procesos de desarrollo territorial. Pasos: Revista de Turismo y Patrimonio Cultural 9 (1), 101-113

ZUBIMENDI, M., H HAMMOND, L. ZILIO, P. AMBRÚSTOLO y A. CASTRO. (2014). "Análisis de los agentes de alteración del registro arqueológico identificados en la costa norte de Santa Cruz (Patagonia, Argentina)." Anales de arqueología y etnología, 2015-2016, vol 70 -71, 159-180

ZUBIMENDI, M.A. y SAMPAOLI, P. (2020) El mundo rural y la Patagonia Rebelde en el noreste de Santa Cruz a comienzos del siglo XX. Actualización de las investigaciones en Patrimonio Cultural realizadas en Santa Cruz. Secretaría de Estado de Cultura. Santa Cruz.

\section{Fuentes}

- $\quad$ www.servicios.infoleg.gob.ar

- www.saij.gob.ar

- www.santacruzpatagonia.com.ar

- www.argentina.gob.ar/turismoydeportes

- www.ruta-de-la-huelga-de-1921.webnode.com

- https://www.municipalidad-argentina.com.ar

- http://www.tageo.com 